\title{
Abstracts of the
}

\section{British Medical Genetics Conference}

\author{
held in Nottingham on 23 to 25 September 1992 (sponsored by the Clinical \\ Genetics Society and the Clinical Molecular Genetics Society)
}

\section{Preimplantation diagnosis of sex in $X$ linked disease by fluorescent in situ hybridisation}

\section{K GRIFFIN*, A H HANDYSIDE $\dagger$, L J WILTON‡, R M L WINSTON†, J D A DELHANTY*}

*The Galton Laboratory, Dept of Genetics and Biometry, UCL, 4 Stephenson Way, London NW1. †RPMS, Hammersmith Hospital, DuCane Road, London W12. $\ddagger$ Institute of Zoology, Regent's Park, London $N W 1$.

We have used four approaches to sexing human blastomeres using the technique of fluorescent in situ hybridisation (FISH) The first and second involve using $\mathrm{Y}$ and $\mathrm{X}$ chromosome specific probes respectively in single hybridisation experiments. Although good efficiency of hybridisation is obtained, each strategy has drawbacks and could lead to males being diagnosed as females because of failure of hybridisation ( $\mathrm{Y}$ probe) or because of tetraploid nuclei (X probe). The third is a dual FISH approach using two $Y$ chromosome probes and one $\mathrm{X}$ chromosome probe. Here the possibility of diagnosing males as females is virtually eliminated, but it takes 24 hours to perform alone and thus does not allow biopsy, spreading, diagnosis, and transfer within the 24 hour period. The fourth approach is a rapid dual FISH sexing strategy taking six to seven hours and giving more reliable results than the above approaches. It is this method which has been put into clinical practice. Ten patients, each carrying $\mathrm{X}$ linked disorders, have had preimplantation diagnosis of sex in this way in a total of 12 treatment cycles. In the first eight cycles biopsy was on day 2 post-fertilisation and cells were allowed to divide overnight before FISH diagnosis. In the final four, biopsy, spreading, FISH diagnosis, and transfer were all on day 3 . It is the latter strategy which has proven to be the most effective in terms of number of nuclei positively diagnosed.

\section{Preimplantation diagnosis of cystic fibrosis by DNA amplification from single cells}

A H HANDYSIDE*, J LESKO†,
J J TARIN*, R M L WINSTON*, J J TARIN*, R M
M R HUGHES $†$

*Institute of Obstetrics and Gynaecology, RPMS, Hammersmith Hospital, Du Cane Road, London W12 0NN. +Institute for

The next British Medical Genetics Conference will be held at Leeds University on 22 to 24 September 1993. Further details are available from Dr Pete Farndon, Clinical Genetics Society, Birmingham Maternity Hospital, Edgbaston, Birmingham B15 2TG. (Tel/fax 021627 2634.)
Molecular Genetics and Center for Reproductive Medicine, Baylor College of Medicine, Houston, Texas 77030, USA.

A polymerase chain reaction (PCR) protocol with nested primers has been developed for amplification of a fragment including the site of the predominant deletion $(\Delta \mathrm{F} 508)$ of the CFTR gene causing cystic fibrosis (CF) from single cells. The presence of the deletion in the amplified fragment is then detected by intentional heteroduplex formation in $\mathrm{mix}$ tures with previously amplified DNA from normal or homozygous deleted cells and gel electrophoresis. Extensive preliminary analysis with single cells, including blastomeres from cleavage stage human embryos, showed that amplification efficiency was high and, to date, the genotype of the original cell has always been correctly identified when analysed blind. Thus, it is possible to diagnose the $\Delta$ F508 deletion within seven to eight hours and transfer selected unaffected or carrier embryos later the same day as cleavage stage embryo biopsy. Preimplantation diagnosis of cystic fibrosis was attempted in three couples in which both partners carry the $\Delta \mathrm{F} 508$ deletion. In vitro fertilisation techniques were used to recover several oocytes from each woman and fertilise them with the husband's sperm. Normally fertilised cleavage stage embryos were biopsied on the third day post-insemination and one or two cells removed for DNA analysis. In one couple, only two oocytes fertilised normally. DNA analysis failed with one of the embryos and the other was diagnosed as affected so none was transferred. In the other two couples, three unaffected or carrier and several affected embryos were identified. Both couples chose to have one normal and one carrier transferred to the uterus later on the same day as biopsy and diagnosis. One of these women became pregnant and has now given birth to a normal girl, unaffected by CF, and free of both the parental mutant alleles.

\section{Reliability of single cell PCR}

CAROLYN WILLIAMS, ROBERT WILLIAMSON

NW Thames Regional DNA Laboratory, Department of Molecular Genetics, St Mary's Hospital Medical School, London W2 $1 P G$.

The polymerase chain reaction has been shown to be capable of amplifying a single molecule of a single locus sequence to visibly detectable amounts of specific signal. We have analysed over 500 single sperm for the $\Delta F 508$ mutation causing cystic fibrosis from a known carrier of this deletion. The method of amplification used for the analysis of very small amounts of DNA template required two rounds of PCR. In the second round a nested set of primers, internal to those used in the first round, is used to reamplify a small aliquot of the product from the first round PCR. When this method has been successful the product from the second round of PCR is easily visualised after gel electrophoresis under UV light. We have also achieved similar results with a coamplification system, where sex chromosome specific primers are added to the first round reaction. A comparison of the $\Delta F 508$ mutation and the normal sequence has shown the incidence to be 45:50 respectively. A comparison of $\mathrm{X}$ and $\mathrm{Y}$ bearing sperm has shown the incidence to be 50:50. The average rate of success for the coamplification of single sperm in our hands is $\sim 65 \%$. There are many possible reasons for this. The accuracy of the FACS sorter adding a single cell to each of a 96 well microtitre plate was shown to be $99 \%$. Cell lysis liberating the genomic DNA for PCR is the first critical chemical reaction and can be hampered if the cell adheres to the plastic wall of the wells or if the sulphidryl reduction is not effective. These data indicate the need for more rigorous testing before single cell PCR can be used routinely for genome analysis, although we have shown there does not appear to be any meiotic drive for CFTR.

\section{Diagnosis of APKD by genetic markers and ultrasonography}

R G ELLES, K A HODGKINSON, N P MALLICK, D J O'DONOGHUE, A P READ, S RIMMER, E A WATTERS, R HARRIS

Departments of Medical Genetics, Renal Medicine, and Radiology, St Mary's Hospital and Manchester Royal Infirmary, Manchester.

The aim of this study was to assess the effectiveness of ultrasonography and molecular techniques in the presymptomatic diagnosis of APKD. The data were collected from a voluntary register of 150 APKD families. An independent calculation of the age dependent false negative rate of ultrasonography in subjects at $50 \%$ risk of inheriting the APKD gene was $4 \%$ in the second and third decades. Twenty-two families were informative for multipoint linkage analysis. Using this method we calculate that the upper limit for the prevalence of APKD transmitted at the PKD2 locus is $4.5 \%$. When these figures were included in individual risk assessments, $83 \%$ of subjects at $50 \%$ prior risk could be assigned a modified risk category with an error rate of $5 \%$ or less. 


\section{Phenotype and genotype heterogeneity in autosomal dominant polycystic kidney disease}

D RAVINE*, R G WALKER $\dagger$,

R N GIBSON $\ddagger$, S M FORREST $\S$, R I RICHARDS |, K FRIEND\|, L J SHEFFIELD\&, P KINCAIDSMITH†, D M DANKS $\S$

*Institute of Medical Genetics, Cardiff. †Department of Nephrology, Royal Melbourne Hospital. $\ddagger$ Department of Radiology, Royal Melbourne Hospital. §Murdoch Institute, Royal Children's Hospital, Melbourne. ||Department of Cytogenetics and Molecular Genetics, Adelaide Children's Hospital.

A study of autosomal dominant polycystic kidney disease (ADPKD) identified 18 families (285 affected subjects) with mutations at the PKD1 locus linked to the $\alpha$ globin complex on chromosome 16 and five families (49 affected subjects) in which involvement of this locus could be dismissed (non-PKD1). Comparison of clinical features showed that non-PKD1 patients lived longer $(p=0.005)$, had a lower risk of developing renal failure $(p<0.05)$, were less likely to have hypertension (odds ratio: $3.32,95 \%$ CI $1.34-8 \cdot 24$ ), were diagnosed at an older age $(p=0.004)$, and had fewer renal cysts present at the time of diagnosis $(p<0.01)$. While the majority of PKD1 families were ascertained through clinics treating patients with renal impairment, none of the non-PKD1 families came from this source $(p<0.05)$. It is likely that the current estimates of the proportion of unlinked families, based predominantly on families ascertained from dialysis and renal transplant programmes, are underestimates of the true prevalence of non-PKD1.

\section{Detection of germline mutations in the APC gene in FAP families}

Y WALLIS*, F MACDONALD*, D MORTON $\dagger$, C MCKEOWN*, R FODDE $\ddagger$ R VAN DER LUIJT $\ddagger$, B RENAUL T $\ddagger$, P MEERA KHAN $\ddagger$, M KEIGHLEY $\dagger, M$ HULTÉN*

*DNA Laboratory, Regional Genetics Service, and $†$ Department of Surgery, Birmingham. $\ddagger$ Department of Human Genetics, University of Leiden, Leiden, The Netherlands.

Familial adenomatous polyposis is an autosomal dominantly inherited condition predisposing to the development of colorectal adenomatous polyps with the inevitable progression to colorectal cancer. The recent isolation of the causative APC gene has enabled the direct detection of mutations in affected subjects allowing accurate presymptomatic diagnosis in at risk family members. Worldwide, preliminary studies have identified 50 to 60 different germline mutations in this gene. We have chosen the technique of denaturing gradient gel electrophoresis (DGGE) as the most sensitive with which to screen FAP families for APC gene mutations (Fodde et al, 1992). To date, $71 \%$ of the coding region has been screened for germline mutations in DNA samples from 16 FAP and two sporadic colorectal cancer patients.
Twelve DGGE variants have so far been identified and, of these, 11 have been characterised by sequencing. Four base substitutions in exons $5,7,8$, and 10 and seven frameshift mutations, all in exon 15 , have been identified; 5 bp deletions at codons 1061 and 1309 have each been found twice in unrelated families. Preliminary phenotypegenotype correlations between CHRPE status and the nature and distribution of these APC gene mutations have been made.

\section{Discrepancy in the estimation of relative male and female mutation rates for Duchenne muscular dystrophy}

\section{STEPHEN ABBS*, ROBIN M WINTER $\dagger$, MARTIN BOBROW*}

*Paediatric Research Unit, UMDS, Guys Hospital, London SE1 9RT. †Kennedy Galton Centre, CRC, Northwick Park Hospital, Middlesex HA1 3 UF.

Analyses of the relative male and female mutation rates giving rise to Duchenne muscular dystrophy have generally concluded that the two rates are equal. Two recent reports from the direct analysis of deletion mutations (van Essen et al, 1992), and an indirect analysis on both deletion and nondeletion mutations (Muller et al, 1992) also concluded that the rates were approximately equal. We have estimated statistically the relative rates in (1) deletion cases, by determining the proportion of carrier mothers among a population of isolated cases; and (2) in non-deletion/duplication cases, by determining the grandparental origin of the mutant $\mathrm{X}$ chromosomes. In both cases the relative mutation rates appeared to differ significantly from a 1:1 ratio, by finding in (1) significantly fewer mothers of isolated cases to carry a deletion, and in (2) a higher number of mutant $\mathrm{X}$ chromosomes to be of grandpaternal origin, when compared with a model of equal male and female mutation. The discrepancy between our data and those of recent studies can be explained by a significant level of mosaicism in the different studies, since none of the methods was able to take this into account directly. This suggests that a more detailed molecular approach is required to resolve the question of new mutations in DMD.

\section{Fetal echogenic bowel and cystic fibrosis in low risk fetuses}

\section{LYN CHITTY*, SIMON DEAR*, KYPROS NICOLAIDES $\dagger$}

*Division of Medical \& Molecular Genetics, UMDS, Guy's Hospital, London. †Harris Birthright Centre, King's College Hospital, London.

Sonographic demonstration of increased echogenicity of the fetal bowel in the second trimester is known to be associated with cystic fibrosis (CF). In a series of 200 fetuses at high risk of having $\mathrm{CF}$, ultrasound examination showed echogenic bowel in 50 to $60 \%$ of affected fetuses. However, there are several other causes of this observation which include an incidental finding, intrauterine growth retardation, congenital infec- tion, and other abnormalities of the fetal bowel. The incidence of echogenic bowel in the low risk population and the relative contribution of the different underlying pathologies is unknown. This makes the initial estimation of risk and counselling of parents following an unexpected finding of echogenic bowel difficult. Until recently the only diagnostic test available for $\mathrm{CF}$ in these circumstances was measurement of amniotic fluid microvillar enzymes, but this can be associated with erroneous results, particularly where the prior risk is low. With the identification of the CF gene and mutations within it we are now able to offer a more accurate diagnostic test in $78 \%$ of cases. We have experience of eight cases where echogenic bowel was detected with ultrasound in low risk fetuses. The parents and/or fetus were screened for mutations in the CF gene. In three cases the parents were found to be heterozygous for the $\Delta \mathrm{F} 508$ mutation and subsequent testing showed that the fetus was homozygous. In all cases the parents elected to interrupt the pregnancy and necropsy confirmed the presence of a significantly dilated ileum filled with meconium. In the fourth case analysis of a fetal blood sample showed that the fetus carried both the $\Delta \mathrm{F} 508$ and GSS1D mutations. At birth the neonate had meconium ileus requiring surgical treatment. Our observations have confirmed the association of echogenic bowel with cystic fibrosis. However, counselling of parents after the incidental finding of echogenic bowel at a routine second trimester ultrasound examination is difficult as there are no low risk population data available. There is clearly a need to establish a study to determine the significance of this finding in the general population.

\section{Glucokinase gene mutation in type 2 diabetes mellitus}

M STOFFEL*, P PATEL †, Y-M D LO§, A T HATTERSLEY $\ddagger$,

A M LUCASSEN\|, R PAGE $\ddagger$, J I BELL\|, G I BELL*, R C TURNER J S WAINSCOAT $\dagger$

${ }^{*}$ Howard Hughes Medical Institute and Departments of Biochemistry and Molecular Biology, and Medicine, University of Chicago, Chicago, IL 60637, USA. $\dagger$ Department of Haematology, fohn Radcliffe Hospital, Oxford OX3 9DU. \pm Diabetes Research Laboratories, Radcliffe Infirmary, Oxford OX2 6HE. \$Nuffield Department of Pathology and Bacteriology, fohn Radcliffe Hospital, Oxford OX3 9DU. |Institute of Molecular Medicine, fohn Radcliffe

Hospital, Oxford OX3 9DU.

Type 2 diabetes mellitus is among the commonest metabolic diseases but despite much research its aetiology has remained largely unknown. There is a strong genetic component as illustrated, for example, by the high level of concordance between identical twins and this has given impetus to genetic studies of diabetes. Progress has been made recently by the demonstration of linkage of a marker near the glucokinase gene on chromosome $7 p$ to a subtype of type 2 diabetes known as maturity onset diabetes of the young (MODY) in French and British pedigrees. We have now characterised a mutation in the glucokinase gene in the British pedigree and have found a codon 299 mutation in exon 8 
resulting in a substitution of glycine to arginine. Fifty patients previously diagnosed as having classical type 2 diabetes mellitus wer screened for this mutation and one furthe patient was found to have this exon 8 mutation. This patient was a member of a larg family with multiple affected members; al the 10 subjects in this family who have inher ited the mutation have type 2 diabetes. The discovery that glucokinase gene mutation may cause MODY and a proportion of late onset type 2 diabetes should facilitate further progress in understanding the metabolic and genetic basis of type 2 diabetes.

\section{Cloning of a candidate gene for Menkes syndrome spanning the MNK translocation breakpoint}

G GIACOMO CONSALEZ* $†$, JOSEPH GECZ , CAROL L STAYTON* BRANKA DABOVIC*, BARBARA PASINI*, PATRIZIA BICOCCHI*, VIRGINIA BARONE*, MICHEL FONTES $\ddagger$, GIOVANNI ROMEO*

* Laboratory of Molecular Genetics and Cytogenetics and $\dagger$ Department of Pathology, Istituto G Gaslini, 16148 Genova Quarto, Italy. $\ddagger I N S E R M$ U242, BP24, 13351 Marseille Cedex 5, France.

The gene responsible for Menkes syndrome has been assigned to Xq13 by a combination of comparative mapping and linkage analysis. A previous report has mapped the translocation breakpoint (Kapur et al, 1986) associated with the disease in a female patien to an interval delimited by $P G K 1$ and a group of six more proximal Xq13 markers, including $D X S 56$. A cosmid (cF11) located $30 \mathrm{~kb}$ from a translocation breakpoint associated with Menkes syndrome in a female patient (Consalez et al, 1992) was used to screen a fibroblast cDNA library. Several positive clones were isolated and found to hybridise a $9 \mathrm{~kb}$ transcript on numerous different tissues, including muscle, heart, brain, fibroblast, pancreas, and, to a lesser extent, liver, lung, and kidney. The same clones were in turn used to screen a total of five cDNA libraries constructed from fibroblast, fetal brain, human skeletal muscle, and $\mathrm{HeLa}$ cells. As a result, a contig of over $30 \mathrm{cDNA}$ clones has so far been developed, spanning the translocation breakpoint and extending over a $250 \mathrm{~kb}$ genomic region. A putative promoter region has been identified $350 \mathrm{~kb}$ distal to locus $D X S 56$. Automated sequencing of the gene has disclosed a $4 \mathrm{~kb}$ ORF directed distal to proximal, encoding a 1300 aa protein, disclosing homologies to cytochromes, ceruloplasmin, and zinc binding peptides. Work is in progress to define the key functional domains and physical structure of this protein.

\section{A splice site mutation of the COL4A5 gene detected by DGGE causes Alport syndrome}

R C TREMBATH, J ZHOU, G SA, T M BARRATT, S MALCOLM K TRYGGVASON
Institute of Child Health, London. Department of Biochemistry, University of Oulu, Finland.

Alport syndrome is an $\mathrm{X}$ linked disorder characterised by sensorineural deafness and nephritis. Electron microscopic examination shows patchy thinning and thickening of the glomerular basement membrane. A new collagen (COL4A5) has recently been identified and assigned to $\mathrm{Xq} 22$, the same region as Alport syndrome. A small number of deletions and rearrangements of the COL4A5 gene have been reported, but the majority of disease alleles are likely to arise consequent to point or small DNA sequence alterations. We have looked for mutations in 18 patients affected by Alport syndrome and two with the histologically distinct disorder, thin membrane disease. The COL4A5 genomic sequence has at least 50 exons. Following computer simulation, GC clamped primers have been generated for a number of exons. Single base changes have been detected by DGGE of PCR amplified genomic DNA. We report a $G$ to $A$ substitution of the last nucleotide of exon $14\left(3^{\prime}\right)$ in brothers with marked sensorineural hearing loss, haematuria, and mild renal impairment at the ages of 17 and 12 years respectively. The base change predicts either a Gly to Ser amino acid substitution or a splice donor site mutation. Illegitimately transcribed lymphocyte COL4A5 mRNA from the carrier mother is composed of two populations, one reduced in size compared to the normal. Sequencing will confirm whether this mutant molecule arises through exon skipping.

\section{A prospective study on the effect of inbreeding: 1986-1992}

\section{S BUNDEY, H ALAM, R J LANCASHIRE}

Departments of Clinical Genetics and Social Medicine, University of Birmingham, Birmingham.

The UK born Pakistanis offer an opportunity to investigate the effects of inbreeding in a developed country, and Birmingham is well suited for such a study. A prospective survey started with births in 1986 and the 4934 babies enrolled then have been followed up for five years. These index children were born to 2432 European mothers, 509 AfroCaribbeans, 625 Indians, 956 Pakistanis, 216 Bangladeshis, and 196 mothers of other races. There were $657(69 \%)$ Pakistan mothers related to their husbands, usually more closely than first cousins. The mean inbreeding coefficient of their children was 0.0686 . The offspring of the consanguineous Pakistanis suffered three times the amount of mortality and morbidity compared to the other ethnic groups. Such offspring had a $1 \%$ risk for early death owing to congenital malformations, a $2 \%$ risk for death before the age of 5 from other causes, and a $7 \%$ risk for a severe chronic illness or disability, which was accompanied by mental retardation in half the cases. Since the socioeconomic features of non-consanguineous Muslim were the same as consanguineous Muslims, the excess risk for severe health problems suffered by the latter group is attributable to inbreeding.
The teaching of ethical aspects of medical genetics in undergraduate medicine

\section{DE WILCOX}

University of Glasgow.

Medical genetics has a long history in the undergraduate curriculum at the University of Glasgow. In a five year course students have 25 hours of preclinical and 15 hours of clinical teaching. Many students' questions in small group teaching concerned ethical aspects and a reorganisation of the whole fourth year curriculum in 1991 allowed an experimental formal discussion of ethics during a three hour morning session at the end of the course. To keep the students' interest, an interactive session was planned. In week 1 they were handed a questionnaire which had 18 practical genetic counselling problems which raised issues such as termination of pregnancy, consent, the testing of children, and confidentiality. They were asked to indicate their level of agreement with the suggested solutions; 178 replies from a class of 205 were analysed by computer and the results were discussed in an open forum. The need for awareness of ethical issues was indicated by finding that 17 students who disapproved of termination of pregnancy would not refer one of their patients for prenatal diagnosis; 74 students would give non-medical personnel, such as the police, free access to medical records; 71 would test a child for carrier status; and 105 students would test children for adult onset disease. The success of the session was assessed in two ways; the students rated each lecture on a numerical score. From 186 replies, this session scored highest out of all lectures given that term. Secondly, three multi-choice questions using similar scenarios to the above points were used in the examination. Only two students would not now refer a patient for prenatal diagnosis, one would voluntarily disclose patient records, but 121 would now test a child for adult onset disease! Ethics is now an integral part of the medical genetics course

\section{Medical genetics in the reformed NHS and in Europe}

\section{R HARRIS, J A RHIND}

Genetic Enquiry Centre, Department of Medical Genetics, St Mary's Hospital, Manchester.

Although there appears to be support in Britain from the House of Commons, Government ministers, and patient organisations for augmenting genetic services, no genetics centre currently has adequate resources and there has been no increase in clinical genetic manpower in the last two years. Worse, Wales and at least one English region have devolved genetic services to districts, which is contrary to policy stated by ministers. To improve the situation medical geneticists, assisted by the Royal College of Physicians and others, are developing strategies which it is hoped will maintain integrated regional clinical and laboratory services and achieve well evaluated developments within the environment of NHS Research and Development. Meanwhile there is increasing interest in the ESHG in surveying manpower and training in the EC and be- 
yond, and this will become important in the UK with greater job mobility. We have found that clinical genetics is officially recognised in only four EC countries (Germany, Netherlands, Portugal, and UK) and in six non-EC countries (Austria, Czechoslovakia, Finland, Israel, Norway, and Sweden). In seven EC and five non-EC countries there is no formal recognition. Procedures for accreditation differ and it is currently impossible to assess comparability of role and training of clinical geneticists (almost nothing is known of the comparability of laboratory medical geneticists). Five EC countries (France, Germany, Netherlands, Portugal, and UK) and six non-EC countries (Czechoslovakia, Egypt, Finland, Israel, Norway, and Sweden) report training programmes in clinical genetics with a duration varying from two years (France, Germany) to up to nine years (Denmark). There is, however, general agreement about the skills required by clinical geneticists and consequently about the content of training programmes and in more than half the EC and non-EC countries respondents strongly support the establishment of a European diploma in clinical genetics. The ESHG will make recommendations to EC and national governments to seek official recognition and resources.

\section{Characterisation of a $340 \mathrm{~kb}$ \\ YAC and cDNA enrichment from a region spanning the locus for retinitis pigmentosa $(R P 3)$}

K L DRY, J BROWN, F E PRYDE, L J HARDWICK, D H LESTER, $S$ M BOYLE, D LE PASLIER, A F WRIGHT

\section{MRC Human Genetics Unit, Edinburgh.}

$\mathrm{X}$ linked retinitis pigmentosa has been shown to be genetically heterogeneous with one locus (RP2) localised to $\mathrm{Xp} 11.4-\mathrm{p} 11.2$ by means of genetic linkage, while the other locus $(R P 3)$ is localised to $\mathrm{Xp} 21.1-\mathrm{p} 11.4$ both by genetic linkage and by the analysis of deletions. Two patients have been identified with deletions in the $\mathrm{Xp} 21.1$ region who have retinitis pigmentosa, one of whom (BB) also suffered from DMD, McLeod's syndrome, and CGD. Analysis of these deletions has suggested that the $C Y B B$ locus, responsible for CGD, is the closest distal marker to RP3 and may be close to the proximal BB deletion breakpoint junction (JBB). We have, therefore, isolated a subclone from JBB which is currently being used to characterise this region further. Since $C Y B B$ is the closest distal marker it was used to screen the available YAC libraries by PCR. Pulsed field gel analysis and fluorescence in situ hybridisation (FISH) of a $340 \mathrm{~kb}$ YAC has confirmed that $C G D$ and $\exists B B$ lie within $200 \mathrm{~kb}$ of each other and suggest that this YAC contains the RP3 gene. In addition, we have confirmed the presence of at least three CpG rich regions in the YAC that may represent islands. The YAC was used to isolate expressed sequences from the $R P 3$ region by cross hybridisation to retinal cDNA libraries. Purified YAC DNA fragments were annealed to catch-linkers, amplified by PCR, and immobilised on a filter or attached to streptavidinmagnetic beads using biotinylated PCR primers. Amplified cDNA phage clones were annealed to the YAC. Following a series of stringent washes, bound cDNAs were eluted from the YAC and either put through a second round of enrichment or cloned. By this means cDNA sequences contained within the YAC are selectively enriched. cDNAs isolated using this method are currently being characterised.

\section{An RT-PCR-SSCP strategy for detection of mutations in the gene encoding the $\alpha 1$ chain of type I collagen: application to the analysis of four osteogenesis imperfecta patients}

\section{K MACKAY*, P H BYERS $†$,} R DALGLEISH*

*Department of Genetics, University of Leicester, Leicester. $\dagger$ Departments of Pathology and Medicine, University of Washington, Seattle, USA.

The aim of this research was to develop a general screening strategy for detection of mutations in the gene encoding the $\alpha 1$ chain of type I collagen in patients with osteogenesis imperfecta $(\mathrm{OI})$. The resulting protocol involves five main elements: (1) reverse transcription of total cellular RNA from cultured fibroblasts, (2) PCR amplification from the cDNA of four overlapping segments, each of approximately $1 \mathrm{~kb}$, (3) generation of subfragments of approximately $100 \mathrm{bp}$ to $350 \mathrm{bp}$ in a series of five single or double restriction enzyme digests for each amplified product, (4) analysis of single strand conformation polymorphisms (SSCP) of subfragments, a technique capable of identifying fragments harbouring mutations; analysis of more than one digest at this stage increases the efficiency of detection of mutations and often allows mapping of the mutation to a small region of the amplified product, (5) DNA sequence analysis of the region of interest to define the mutation. Application of this strategy has led to the identification of mutations resulting in glycine to serine substitutions in the $\alpha 1$ chain of type I collagen in four patients with OI. The substitutions are at positions 247 and 352 in patients with lethal phenotypes (Sillence type II) and at positions 382 and 541 in patients with nonlethal phenotypes (Sillence types IV and III, respectively). These results extend our knowledge concerning the relative importance of domains within the collagen chains with respect to their function.

\section{Elucidation of possible mechanisms of sex chromosome non-disjunction using centromere map analysis}

\section{J MACKENZIE*, NE MORTON $\dagger$, P A JACOBS*, T J HASSOLD}

*Wessex Regional Genetics Laboratory, Salisbury District Hospital, Salisbury. $\dagger C R C$ Research Group in Genetic Epidemiology, Princess Anne Hospital, Southampton. $\ddagger$ Dept of Pediatrics, Emory University, Atlanta, Georgia, USA.

We have studied 98 sex chromosome aneuploids of maternal origin with 15 or more highly polymorphic probes to investigate if aberrant recombination is involved in the aetiology of non-disjunction. We have found that 58 of the non-disjunctional events occurred at meiosis I, 17 at meiosis II, four as postzygotic mitotic errors, while as yet 19 are undetermined. Centromere map analysis has shown highly significant differences in the level and distribution of recombination on the $\mathrm{X}$ chromosome between non-disjunctional and normal meiosis. These differences include both complete absence of recombination (Nullochiasmate non-disjunction) and a very marked increase of pericentromeric recombination.

Investigation of mutations of the p53 tumour suppressor gene in fresh and archival ovarian cancer material

E SHERIDAN*, B W HANCOCK*, J SMITH $\dagger$, M H GOYNS*

* Dept Clinical Oncology, Royal Hallamshire Hospital, Sheffield S10 2FF. †Dept of Pathology, Northern General Hospital, Sheffield S5 $7 A U$.

We have investigated the incidence of p53 mutations in fresh ovarian cancer tissue by a combination of chemical cleavage and DNA sequencing of PCR amplified fragments from exons II to IX; these are the regions of the gene that contain the mutation hot spots. To date we have identified mutations in $6 / 22$ specimens. In five of these specimens the mutation would have produced an amino acid substitution in the p53 protein, and in the sixth case the mutation represented a polymorphism. DNA has now also been extracted from paraffin fixed archival material and is being analysed in the same way. The use of archival material should allow correlation between p53 mutations and a variety of clinical parameters, and may provide an indicator of those patients who will benefit from toxic drug treatment.

\section{A variant of the Li-Fraumeni syndrome?}

\section{$S$ MOHAMMED, S HODGSON, D BARNES, C MACGEOCH, N SPURR, M BOBROW}

Guy's Hospital, Imperial Cancer Research Fund.

We describe a mother and daughter with constitutively high levels of p53 protein in their normal tissues. The patients are members of a family with multiple cancers, similar to the spectrum of tumours seen in $\mathrm{Li}$ Fraumeni families, many with an early age of onset. Sequencing of the entire p53 gene and detailed protein analysis in the daughter suggests that she is accumulating high levels of wild type p53. We propose that this phenotype defines a familial cancer susceptibility syndrome, similar to the Li-Fraumeni syndrome, which is defined by high levels of p53 expression in normal tissue. 
Prenatal sex determination from maternal peripheral blood using the polymerase chain reaction

Y-M D LO*, P PATEL $\dagger$, C N BAIGENT $\ddagger, M$ D G GILLMER $\S$, P CHAMBERLAIN\&, M TRAVI $\|_{\text {, }}$ M SAMPIETRO $\uparrow$, J S WAINSCOAT $\dagger$, K A FLEMING*

*Nuffield Department of Pathology and Bacteriology, fohn Radcliffe Hospital, Oxford OX3 9DU. †Department of Haematology, fohn Radcliffe Hospital, Oxford OX3 9DU. $\ddagger$ Clinical Trial Service Unit, Harkness Building, Radcliffe Infirmary, Oxford OX2 6HE. \$Maternity Department, fohn Radcliffe Hospital, Oxford OX3 9DU. ||Istituti Clinici di

Perfezionamento, Milan, Italy. IIstituto di Medicina Interna e Fisiopatologia Medica, Universita di Milano, Milan, Italy.

We have investigated the use of a nested PCR assay for the detection of a fetal specific $Y$ chromosomal sequence (DYS14) from DNA extracted from unsorted maternal periphera blood. Serial dilutions of male DNA into female cord blood DNA indicated that the assay could detect an equivalent of a single male cell in 300000 female cells. The assay exhibited absolute specificity for male DNA with no amplification from a panel of 10 female cord blood DNA. When used on DNA extracted from unsorted peripheral blood from a series of 75 pregnant women, concordance between the assay results and fetal sex was observed in 55 cases $(73 \%)$. The assay showed positive predictive values of $86 \%, 67 \%$, and $87 \%$ in the first, second, and third trimesters, respectively. The corresponding negative predictive values were $83 \%, 64 \%$, and $67 \%$, respectively. We have also shown that retesting 44 samples a second time allows detection of a proportion of male bearing pregnancies with a high degree of accuracy in that all 15 women who gave positive signals in two consecutive amplifications had male fetuses. We have also applied the test at eight weeks' postpartum to eight women who had previously delivered male babies and no $\mathrm{Y}$ specific signal could be detected in any of them, thus suggesting that most women have cleared their circulation of fetal cells by eight weeks after parturition.

\section{Biochemical screening for chromosome abnormalities and neural tube defects in the first trimester \\ D A AITKEN*, G MCCAW*, J A CROSSLEY*, E BERRY*, J M CONNOR*, K SPENCER $\dagger$, JN MACRI}

*Duncan Guthrie Institute of Medical Genetics, Yorkhill, Glasgow G38SF. $\dagger$ Clinical Chemistry Department, Oldchurch Hospital, Romford, Essex. $\ddagger$ Research Division, NTD Laboratories, Carle Place, New York, USA.

We have investigated AFP, UE3, intact $h C G$, Free $\beta$ hCG, and PAPP-A in pregnan- cies with various chromosomal and structural abnormalities identified within a series of 14000 consecutive prospectively collected serum samples at 7 to 14 weeks' gestation. In a group of 16 Down's syndrome pregnancies, median MOMs were: AFP 0.65, UE3 0.67, inthCG 0.97, FßhCG 1.96, and PAPP-A 0.58 . Significant correlation was found in the Down's samples for inthCG/F $\beta$ hCG and for PAPP-A/F $\beta$ hCG. In a group of five trisomy 18 pregnancies median MOMs were: AFP 0.71 , UE3 0.34, inthCG 0.27 , F $\beta$ hCG 0.15 , and PAPP-A 0.62. The most effective combination of markers along with maternal age was FBhCG and AFP which gave an estimated 54\% detection of Down's syndrome pregnancies at a false positive rate of $5 \%$ None of 13 pregnancies with open NTD from which maternal serum samples were collected at 8 to 13 weeks' gestation had raised ( $\geqslant 2.0$ MOM) MSAFP. However, matched second trimester samples from the same pregnancies at 16 to 18 weeks all had significantly raised MSAFP levels. No significant differences were found for UE3 and inthCG. Thus, biochemical screening for chromosome abnormalities may be practicable at any gestation from 7 to 20 weeks using AFP, FBhCG, and maternal age. However, a separate screening protocol using AFP at 15 to 20 weeks' gestation would still be required for effective detection of NTD.

\section{Preliminary results of a prospective study of Down's syndrome screening using Free $\beta$ hCG}

\section{K SPENCER, P CARPENTER}

Endocrine Unit, Oldchurch Hospital, Romford, Essex.

Retrospective studies over the past two years have identified that maternal serum Free $\beta$ hCG, in combination with AFP and maternal age, can achieve Down's syndrome detection rates higher than that achieved by total hCG, AFP, and maternal age combinations. To test the true efficiency of this proposed strategy we have undertaken a prospective study. In our pregnant population of 7864 cases we have observed 10 cases of Down's syndrome, which equates to an incidence of 1.3 per 1000 births. Only two cases were in women over 35 years old. Of the 10 cases, eight were identified by the Free $\beta$ hCG/ AFP/maternal age protocol with a Down's syndrome risk of 1 in 300 or greater. To identify these cases, $5.5 \%$ of the pregnant population was identified at increased Down's syndrome risk. Of these women, $89 \%$ accepted an offer of amniocentesis. In addition our screening protocol identified with increased Down's syndrome risk, three cases of Turner's syndrome, two cases of hydronephrosis, one renal agenesis, and seven cases of fetal death. One case of trisomy 13 was also terminated (in a mother over 35 ) in which the Free $\beta$ hCG level was less than $0.65 \mathrm{MoM}$. We conclude that Down's screening programme using Free $\beta$ hCG is the protocol of choice and have shown prospective detection rates of $80 \%$ can be achieved with the added benefit of identifying other abnormalities.
Rapid confirmation of trisomy 18 on interphase cells from venous and cardiac blood smears using a directly fluoresceinated 18 centromere specific probe

\section{J J WATERS*, D N L CARDY*, M STACEY*, C MCKEOWN $\dagger$, M HULTÉN*}

*Regional Cytogenetics Laboratory, East Birmingham Hospital, Birmingham B9 5ST $\dagger$ Department of Clinical Genetics, Birmingham Maternity Hospital, Birmingham B15 2TG.

We present three cases where in situ hybridisation to whole blood smears using a directly fluoresceinated, centromeric probe, Chromoprobe 18, allowed the detection of trisomy 18 (as determined by the presence of three signal spots) in interphase cells with the minimum of sample and probe preparation time. In two cases postnatal confirmation of trisomy 18 detected at amniocentesis was possible after TOP (case 1: 14/67, control 0/ 50 ; case 2: $26 / 40$, control $1 / 55$, three signal spots observed). In the third case a newborn baby with ?Edwards syndrome requiring surgery was provisionally diagnosed as trisomy 18 within 24 hours (case 3: 59/163, control $2 / 104$, three signal spots observed). Conventional cytogenetic analysis at 48 hours confirmed this finding. By minimising sample and probe preparation time and removing the need for post-hybridisation signal amplification, detection of simple trisomies is possible within three to four hours of sample receipt using this approach.

\section{Chiasma frequency, quadrivalent orientation, and first meiotic segregation in a human male reciprocal translocation heterozygote} $t(15 ; 20)(q 13 ; q 13.1)$ analysed by dual colour fluorescence in situ hybridisation

\section{A S H GOLDMAN, M A HULTÉN}

Regional Genetics Services, DNA

Laboratory, East Birmingham Hospital, Birmingham B9 5PX.

Chiasma frequency, quadrivalent orientation, and first meiotic segregation has been investigated in a human male with the karyotype $46, X Y, t(15 ; 20)(q 13 ; q 13.1)$. The rearranged chromosomes were identified by dual colour fluorescence in situ hybridisation using the whole chromosome library pBS20 in combination with the paracentromeric probe $\mathrm{D} 15 \mathrm{Z} 1$. At first metaphase (MI) the chiasma distribution in the quadrivalents was assessed directly. At second metaphase (MII) resolved interstitial chiasmata gave rise to chromosomes bearing one translocated and one normal sister chromatid. Interstitial chiasmata were found in $31.0 \%$ of $87 \mathrm{MI}$ and $32.5 \%$ of $117 \mathrm{MII}$ cells. Examination of the MII cells was used to deduce the segregation patterns. All types of 2:2 segregations, that is, alternate $(14.5 \%)$, adjacent I $(16.2 \%)$, and adjacent II $(39.3 \%)$, as well as $3: 1(1.7 \%)$ and $4: 0(0.9 \%)$ were found. The remaining cells were indistinguishable from 
alternate and adjacent I owing to the presence of interstitial chiasmata $(27 \cdot 4 \%)$. From the numbers of each segregational type found it has been predicted that this structural heterozygote would produce balanced, normal, and unbalanced gametes in the proportions $13.4 \%, 15 \cdot 1 \%$, and $71 \cdot 5 \%$ respectively.

\section{Variability of clinical, genetic, and protein abnormalities in manifesting carriers of $X_{p} 21$ muscular dystrophy}

\section{K M D BUSHBY, J A GOODSHIP, L V B NICHOLSON, I D HAGGERTY, D GARDNER-MEDWIN}

Departments of Human Genetics and Neurobiology, University of Newcastle upon Tyne.

We have collected clinical, molecular, and dystrophin data on eight manifesting carriers of Xp21 muscular dystrophy. Their clinical course varied from Duchenne-like to a slow Becker-like progression. One girl presented with predominantly intellectual problems. Only two had a previous family history of Xp21 dystrophy, none had abnormal karyotypes, and none were twins. Dystrophin was abnormal on both immunocytochemistry and immunoblotting in all patients; in three the diagnosis was made only after dystrophin examination of stored muscle biopsy samples. One girl, the obligate carrier daughter of a patient with BMD with a known deletion, presented with muscle problems and developmental delay aged 2 years. Immunoblotting of her muscle sample for dystrophin clearly showed two bands, reflecting the products of her two $\mathrm{X}$ chromosomes. In the others, only a single band of reduced abundance was detected, consistent with there being no cDNA deletion. In all patients, dystrophin abundance on immunoblotting was in the range associated with a relatively mild clinical course. In the obligate BMD carrier, there was no evidence for abnormal $\mathrm{X}$ inactivation in lymphocytes or muscle; however, the three other manifesting carriers for whom $\mathrm{X}$ inactivation studies in lymphocytes were informative did have skewed or non-random patterns. The range of abnormalities seen in manifesting carriers reflects the spectrum seen in males with Xp21 muscular dystrophy. Dystrophin analysis seems to be reliable in making the diagnosis.

\section{The Oxford neurofibromatosis clinic: the first two years' experience}

\section{S M HUSON, J CASTLE, E ROSSER}

Department of Medical Genetics, Churchill Hospital, Oxford $O X 37 \mathrm{LF}$.

The Oxford neurofibromatosis (NF) clinic began in January 1990 with the specific aims of providing follow up for local families and to provide specialist assessment of cases where the type of NF was uncertain and for advice about management of particularly rare complications. The protocol for follow up used was that recommended by Huson et al ( $\mathcal{F}$ Med Genet 1989;26:712-21) that children should be seen twice yearly and adults yearly for a general medical examination to monitor for complications but that no specific screening investigations should be done. One or more family members from 101 families have been seen. The major referral reasons have been confirmation of diagnosis $(19 \%)$, for genetic counselling $(17 \%)$, and for specialist advice regarding NF (64\%). Eight percent of those with a referral diagnosis of NF1 had a different final diagnosis; these included segmental neurofibromatosis, multiple lipomatosis, infantile myofibromatosis, and urticaria pigmentosa. The only major disease complications identified through the clinic were plexiform neurofibromas $(7 \%)$ which were already present but their significance had not been appreciated by the referring clinician. However, major changes in management have been advised; $30 \%$ were not under regular follow up before attending the clinic, and in approximately $40 \%$ of the children seen, educational difficulties were being experienced and had not been specifically identified as being related to NF1. There have been no prenatal diagnoses for NF1 from the clinic population to date, although three couples have requested informativeness testing. The clinic experience to date suggests: (1) there is still a need to improve awareness of NF by health professionals; (2) twice yearly routine appointments for children have proved too frequent; (3) even in a specialist clinic population, most complications are relatively infrequent and will require multicentre collaboration to improve knowledge of natural history and assessment of different treatment modalities.

\section{Gorlin syndrome and congenital} anomalies in medulloblastoma

\section{G R EVANS, H RAO \\ GATTAMANENI, P A FARNDON, L D BURNELL, R CAMPBELL, J M BIRCH}

Christie Hospital and St Mary's Hospital, Manchester.

Gorlin syndrome (GS) is an autosomal dominant disorder characterised by multiple basal cell carcinomas, jaw cysts, and skeletal anomalies. There have been nearly 40 reports of its association with medulloblastomas. We have undertaken the first population based study to assess the true level of its incidence in medulloblastoma; 173 consecutive cases of medulloblastoma registered with the Manchester Children's Tumour Registry were studied. Case notes, $x$ rays, and health surveys were reviewed. Two of 173 cases had a definite diagnosis of GS and a further case at $50 \%$ risk of GS was identified. GS accounts for 1 to $2 \%$ of medulloblastoma cases and 3 to $5 \%$ of cases of GS develop the brain tumour. Average age of onset of medulloblastoma in GS is two years (cf $7 \cdot 26$ years). All early onset medulloblastoma cases should be assessed for GS in view of the risk of multiple basal cell carcinomas following radiotherapy. In addition to $\mathrm{GS}$ a high incidence of congenital anomalies and genetic syndromes was found in this series $(6 \cdot 8 \%)$. One case of type 1 neurofibromatosis was found and also previously unreported association with Rubinstein syndrome.
Survival in 'lethal' osteogenesis imperfecta: a case report of concordant twins

\section{J-U WALTHER, D ZAFEIRIOU, A NERLICH, R BRENNER, Th MEITINGER}

\section{Kinderpoliklinik, Munich University.}

Identical twins of consanguineous Turkish parents are reported. There was no family history of skeletal disease. The probands were born by caesarean section at 34 weeks' gestation. Clinically they showed the characteristic features of severe osteogenesis imperfecta (OI) with short limbed dwarfism, curved extremities, soft skull, craniofacial dysmorphism, and blue sclerae. Radiologically OI IIb was diagnosed on the basis of generalised osteopenia, thin fractured ribs, moderate platyspondyly, and short and broad femora with numerous fractures. Initial respiratory problems improved after 24 hours of mechanical ventilation and both children were discharged home at eight weeks. One patient died at home from sudden cardiorespiratory insufficiency at 13 weeks. Necropsy showed right ventricular hypertrophy. Her twin sister at eight months is in a stable condition with slowly developing motor activity and slight improvement of bone density. Protein analysis showed normal amounts of procollagen synthesis, but slightly reduced electrophoretic mobility of both $\alpha 1(\mathrm{I})$ and $\alpha 2(\mathrm{I})$ chains, suggestive of post-translational overmodification. This report of twins concordant for a rare recessive(?) form of OI IIb indicates how the prognosis of so called lethal disorders may depend on peri- and neonatal management. In addition it serves as a model for studying intrafamilial phenotypic variability of an identical OI mutation.

\section{A new mental retardation syndrome mapping to the pericentromeric region of the $X$ chromosome}

\section{ME M PORTEOUS, H JOHNSON, J BURN, A CURTIS, S LINDSAY, S S BHATTACHARYA, J A GOODSHIP}

Department of Human Genetics, University of Newcastle upon Tyne.

A new $\mathrm{X}$ linked mental retardation syndrome characterised by short stature, high pitched voice, high forehead, and receding hairline is described in a four generation family. Testicular volume and head circumference are normal in affected males. Cytogenetic testing has shown no evidence of fragile $\mathrm{X}$. Obligate female carriers show no features of the condition. Linkage studies using $\mathbf{X}$ chromosome derived microsatellite markers have localised the gene responsible to the pericentromeric area bounded by $M A O A(\mathrm{Xp} 11.3-11.4)$ and $D X S 566$ (Xq13). A maximum lod score of 3.15 at $\theta 0$ is obtained from two point analysis of the disease locus versus the androgen receptor locus (Xq12) 
Terminal deletions of $2 \mathrm{q}$ : is there a consistent phenotype?

\section{A OLEY*, J WOLSTENHOLME*, S COULTHARD*, J A BRUMMITT*, C J ENGLISH*, I A CROSS*, A P READ $\dagger$}

*Northern Region Genetics Service, 19/20 Claremont Place, Newcastle upon Tyne. $\dagger$ Dept of Medical Genetics, St Mary's Hospital, Manchester.

Only two cases of deletions of the long arm of chromosome 2 involving band $\mathrm{q} 37$ have been reported previously. We present four unrelated subjects with similar terminal deletions of 2q. Their ages ranged from 15 months to 17 years at the time of diagnosis. All four had varying degrees of mental retardation. Consistent dysmorphic features were large, prominent ears with large fleshy lobes and eczema in all four; three had upward slanting palpebral fissures, fine or sparse scalp hair, sparse eyebrows and eyelashes, with normal teeth and nails. Our findings of four terminal deletions of $2 \mathrm{q}$ among about 2500 case referred over five years for developmental delay would suggest that this deletion may be underdiagnosed.

\section{Absence of facial involvement may differentiate a scapular onset form of muscular dystrophy from FSH dystrophy}

\section{PE JARDINE*, P W LUNT*, $M$ UPADHYAYA $\dagger$}

*Clinical Genetics Unit, Institute of Child Health, Bristol Children's Hospital, Bristol. $\dagger$ Institute of Medical Genetics, University of Wales College of Medicine, Cardiff.

We have examined 13 subjects in a family of whom seven are affected with a dominantly inherited muscular dystrophy with presentation and course similar to facioscapulohumeral muscular dystrophy (FSHD) except for consistent absence of facial weakness. Onset was in the shoulder girdle muscles in the second to fourth decades. In $2 / 7$ weakness progressed to humeral muscles and to proximal and distal lower limb muscles, affecting ambulation. Contractures, pseudohypertrophy, and cardiac involvement were not present. CK was moderately raised in some subjects up to $1.5 \times$ normal limit. Muscle biopsy from the proband showed myopathic changes consistent with muscular dystrophy and nerve conduction was normal. Precise diagnostic classification in this family is difficult. On clinical grounds the condition should be differentiated from FSHD and from known limb girdle, scapulohumeral, and scapuloperoneal syndromes. DNA typing performed at 4q35 loci D4S139 and $D 4 S 163$, which are known to be closely linked to $F S H D(\theta \max \leqslant 0.05)$, gave a lod score at $\theta=0.05$ of -1.44 or +1.95 depending on grandparental haplotyping, and was therefore inconclusive. The identification of a closer marker or of a restriction fragment associated with FSHD would resolve this difficulty and help clarify the importance of facial weakness as a cardinal feature of FSHD.

\section{Two cases of aneuploidy and the fragile $X$ syndrome}

\section{A J BARNICOAT*, $M$ DAKER*, F BIRJANDI*, Q WANG*, W G VAN'T HOFF $\dagger, M C$ SANDERSON}

*Department of Medical and Molecular Genetics, and $†$ Department of Paediatrics, Guy's Hospital, London. $\ddagger$ Department of Paediatrics, All Saints' Hospital, Chatham.

Case 1. A 9 month male infant was referred for chromosome analysis because of developmental delay and dysmorphic features. He had brachycephaly, hypertelorism, and epicanthic folds. Echocardiography confirmed patent ductus arteriosus and mitral regurgitation. His karyotype was $49, \mathrm{XXXY}$, fra $(\mathrm{X})$ (q27.3) (30\% expression). Case 2. A female neonate born at 37 weeks' gestation was referred for assessment. She had dysmorphic features with simple, low set ears, a posterio cleft palate, bifid tongue, and polydactyly. A perimembraneous ventriculoseptal defect was diagnosed on echocardiography. $\mathrm{Her}$ karyotype was $47, \mathrm{X}, \mathrm{fra}(\mathrm{X})(\mathrm{q} 27.3)+13(28 \%$ expression). The concurrence of fragile $\mathrm{X}$ syndrome with aneuploidy is well reported, particularly with additional $\mathrm{X}$ chromosomes. Both of these children were diagnosed as having fragile $\mathbf{X}$ after a few fragile sites were seen on initial unstressed cultures, later confirmed after culture in standard fragile $X$ media. It is important to follow up such findings on unstressed cultures even in the presence of abnormalities sufficient to explain the clinical phenotype, to ensure appropriate genetic counselling for other family members.

\section{$\mathrm{X}$ linked} adrenomyeloneuropathy misdiagnosed as multiple sclerosis in a manifesting heterozygote

\section{J C MACMILLAN*, S BISHARA $\dagger$,} $M$ SKEAFF

Depts of Neurology*, Neurosurgery $\dagger$, and Human Nutrition $\ddagger$, University of Otago, Dunedin, New Zealand.

A 26 year old female was referred for assessment of diplopia, progressive difficulty in walking, and urinary frequency. The second of three sibs, she had been diagnosed as having suffered an episode of transverse myelitis (? multiple sclerosis) with resultan weakness and spasticity in both legs at the age of 13 . She was also assessed as having a familial mental retardation syndrome on the basis of mild intellectual impairment (IQ 68 to 78 ) in common with her older brother Physical examination at the age of 26 showed bilateral abducting and rotatory (on superior gaze) nystagmus, dysarthria, spastic limb weakness, upper and lower limb hyperreflexia (except for absent ankle jerks), extenso plantar responses, and absent vibration sense in the toes. Her gait was ataxic. Neurophysiological assessment confirmed the neuropathy as axonal; CSF analysis was normal. Plasma very long chain fatty acid (VLCFA) analysis showed the level of C26:0 VLCFA to be $1.2 \mu \mathrm{g} / \mathrm{ml}$, the $\mathrm{C} 26 / 22$ ratio to be 0.055 , and the 'discriminant $Y$ ' value was calculated at 1.0205 . These results are compatible with a diagnosis of $\mathrm{X}$ linked adrenoleucodystrophy/adrenomyeloneuropathy. Review of the family history suggested a further two first cousins may also have the disorder. The proband had recently given birth to a baby girl.

\section{Trends in the number of births with spina bifida}

\section{K M LAURENCE}

Institute of Medical Genetics, University of Wales College of Medicine, Heath Park, Cardiff.

The incidence of neural tube defects (anencephaly, encephalocele, and spina bifida) in south Wales fell from 8 per 1000 births between 1956 and 1966, to less than 5 per 1000 in 1973. From then the affected 16 week pregnancies dropped to below 2 per 1000 in 1989. Prenatal diagnosis available since 1974 , and serum AFP and ultrasound screening since 1976 followed by selective abortion, have all but eliminated anencephalic births and reduced spina bifida and encephalocele births to well below 2 per 10000 . Similar falls in incidence have been reported from elsewhere in the UK. Recurrences are now rare and with all pregnancies in the UK having ultrasound screening and over $80 \%$ AFP screening as well, fewer than 80 infants with spina bifida are liveborn per year, with fewer than 50 surviving beyond one year. As screening and surveillance is likely to extend, this number will reduce further unless the trend for termination of pregnancies with malformed fetuses is reversed. Reasons for the fall in the number of affected pregnancies with NTD (as opposed to uncomplicated congenital hydrocephalus) may include an as yet unexplained secular trend, or more likely, improvement in maternal nutrition and demographic changes. This has implications for the incidence of NTD elsewhere in the world.

\section{POSTERS}

\section{Maternal serum screening for Down's syndrome in East Anglia}

S F GOODBURN, J R W YATES, P J RAGGETT, C CARR, A KERSHAW, $M$ A FERGUSON-SMITH

Departments of Clinical Genetics and Clinical Biochemistry, Addenbrooke's Hospital, Cambridge.

In 1991 maternal serum screening was made available to women of all ages attending five maternity hospitals in East Anglia. Amniocentesis was offered when the risk of Down's syndrome at term exceeded 1 in 200 , calculated from maternal age and serum levels of AFP (Delfia), total hCG (Delfia), and unconjugated oestriol (Kodak). A total of 12148 women were screened representing an uptake of $80 \%$. The recall rate was $3.9 \%$ in hospitals which offered dating scans before sampling significantly lower than the $10 \cdot 1 \%$ recall rate in hospitals in which gestation was based on dates $(p<0.0005)$. Amniocentesis was carried out in 399 pregnancies representing $3.3 \%$ of women screened; 14 Down's syndrome pregnancies were identified. Based 
upon an incidence of Down's syndrome of 2 per 1000 in the second trimester, the expected number of affected pregnancies would be 24, giving an estimated detection rate of $57 \%$. With outcomes known for 11 months, only six Down's pregnancies are known to have been missed so that the actual detection rate may be somewhat higher than estimated. If oestriol had not been included in the analyses only 10 Down's pregnancies would have been identified. The other abnormalities detected were trisomy 18 (1), trisomy 13 (1), 46,XY, del 5p15.1 (1), $46, X Y t(9 ; 12)(q 33 ; q 24) \quad(1), \quad 45, X \quad$ (1), $48, \mathrm{XXXY}(1), 69, \mathrm{XXX}$ (3), anencephaly (5), open spina bifida (7), hydrocephalus (5), exomphalos (1), gastroschisis (1), placental sulphatase deficiency (3), missed abortion (31), twin pregnancies (15), and triplets (1).

\section{Biochemical screening for chromosome abnormalities: five years' experience of routine} screening in the west of Scotland

\section{E BERRY, D A AITKEN, J A CROSSLEY, J M CONNOR}

Duncan Guthrie Institute of Medical Genetics, Yorkhill, Glasgow G3 8SF.

In the west of Scotland, before the introduction of biochemical screening, maternal age screening ( $\geqslant 35$ years) resulted in an average annual detection rate of $13 \%$ for Down's syndrome, less than half the possible detection rate of $30 \%$, owing to a low uptake $(<40 \%)$ of amniocentesis. Following the introduction of AFP/age screening in 1987, an analysis of over 100000 pregnancies screened routinely shows that $43 \%$ of Down's pregnancies were identified within a screen positive group of $6.2 \%$ of pregnancies. The overall amniocentesis rate was $42 \%$ and the actual detection rate for Down's $28 \%$. In September 1991, hCG analysis was added to the AFP/age combination. A review of the first 11900 pregnancies of known outcome has shown that $75 \%$ of Down's pregnancies were identified within a high risk group of $5.3 \%$. An increased uptake of diagnostic testing (to $65 \%$ ) has also led to improved detection efficiency with $50 \%$ of all Down's pregnancies being diagnosed prenatally.

\section{Molecular and genetic mechanisms in recurrent severe osteogenesis imperfecta}

\section{D BRIGGS, D MALLERY, S DAW,} F M POPE, A C NICHOLLS

\section{Dermatology Research Group, Clinical} Research Centre, Watford Road, Harrow HA1 3Uf.

We have examined the type I collagen proteins and genes in seven families with recurrence of severe osteogenesis imperfecta (OI) and clinically normal parents. Five families were consanguineous and two non-consanguineous. An eighth family had one affected child born to consanguineous parents. In the two non-consanguineous families we have identified heterozygous mutations in either $C O L 1 A 1$ or COL1A2 and mosaicism in one parent. Of the consanguineous families, two have shown excessively modified type I collagen but RFLP haplotype analysis indicates non-linkage to either COL1A1 or COL1A2. A third was also unlinked by RFLP analysis and showed no overmodification of type I collagen. A fourth showed no protein overmodification but affected children were homozygous at both $C O L 1 A 1$ and $C O L 1 A 2$. The family with the single affected child showed normal protein but homozygosity for RFLPs at the COL1A2 locus. The last consanguineous family showed overmodified type I collagen and homozygosity for RFLPs at the $C O L 1 A 2$ locus. Extensive DNA analysis showed heterozygosity for a sequence polymorphism in the COL1A2 gene in both affected subjects but failed to identify a causal mutation. Recurrent OI appears to be molecularly and genetically heterogeneous. Mosaicism for dominant mutations is most likely for unrelated parents. In consanguineous families the disease may or may not be linked to the type I collagen genes and may or may not be associated with excessive posttranslational modification of type I collagen.

\section{Detection of mutations in part of the APC gene in FAP families and sporadic colorectal cancer}

\section{$S$ COTTRELL, D BICKNELL, S HODGSON, J SMITH-RAVIN, W F BODMER}

Imperial Cancer Research Fund, 44 Lincoln's Inn Fields, London WC2A 3PX.

Familial adenomatous polyposis (FAP) is an inherited autosomal dominant disorder characterised by the development of numerous adenomatous polyps in the colon and rectum with rapid progression to colon carcinoma at an early age. The gene responsible (APC) was localised to 5q21-22 and subsequently cloned. The message is divided into 15 exons, the last of which contains more than $3 / 4$ of the coding sequence. In this study, 14 mutations in nine families and 13 sporadic cancers have been found in a small region of the gene between codons 1028 and 1499 using the technique of single strand conformation polymorphism analysis (SSCP). They all generate stop codons, either by point mutations or small deletions or insertions causing frameshifts. One mutation was found in a sporadic colon tumour, a colorectal cancer cell line and four unrelated FAP patients. This $5 \mathrm{bp}$ deletion produces distinctive heteroduplex bands which can be detected easily using a non-radioactive screen.

\section{p53 mutations in ovarian cancer}

B J MILNER*, L A ALLAN*, D ECCLES§, H KITCHENER $\dagger$, D PARKIN $\dagger$, I MILLER $\ddagger$, K F KELLY*, NE HAITES

*Department of Molecular and Cell Biology (Medical Genetics), †Department of Obstetrics and Gynaecology, $\ddagger$ Department of Pathology, University of Aberdeen. \$ICRF Medical Oncology Unit, Edinburgh.

Using the SSCP (single strand conformational polymorphism) technique and anti-p53 monoclonal antibodies PAb240 and PAb1801, 66 malignant ovarian tumours have been screened for p53 mutation in exons 5 to 8 , and p53 expression, respectively. Thirty-four of the tumours $(52 \%)$ showed an SSCP band shift in this region of the gene, including six in exon 5 , seven in exon 6,12 in exon 7, and 10 in exon 8 (one of the tumours showed a shift for exons 7 and 8). Monoclonal antibody staining was found to correlate with the presence of mutations detected by SSCP analysis, as was chromosome 17 allele loss using $17 \mathrm{p}$ probes $\mathrm{pYNZ22}$ and $\mathrm{pBHp} 53$, and $17 \mathrm{q}$ probe $\mathrm{pTHH} 59$. Presence of p53 mutation did not appear to be prevalent in any particular pathological subgroup of tumours and did not appear to be linked with FIGO staging. Seventeen of the SSCP shifts have been further characterised by DNA sequencing and have all been shown to represent genuine mutations. These include 15 point mutations ( 14 missense and one nonsense) and two deletions (a 2 bp deletion introducing, by frameshift, a stop codon further downstream, and an unusual $6 \mathrm{bp}$ deletion made up of separate $2 b p$ and $4 b p$ deletions). The point mutations, when taken with other published point mutations in ovarian cancer, showed no prevalence of any particular transition or transversion type.

\section{Molecular aspects of P53 in lymphoma and leukaemogenesis}

D J A ADAMSON*, A A DAWSON $\dagger$, B B BENNETT $\dagger$, NE HAITES*

*Department of Medical Genetics, University Medical School, Foresterhill, Aberdeen AB9 2ZD. †Department of Haematology, Ward 47, Aberdeen Royal Infirmary, Foresterhill, Aberdeen AB9 2ZB.

Single strand conformation polymorphism (SSCP) analysis was used to detect P53 mutations (exons 5, 6, 7, and 8) in 30 Hodgkin's and non-Hodgkin's lymphomas. We found 13 mobility shifts, the majority in exons 5 and 7 and none in exon 8 . The lymphomas were also analysed by Southern analysis using the probes pBHP53 and pMCT35.1, which map to the P53 locus, and PYNZ22 (telomeric to P53 on chromosome 17p). Allele loss was detected in 6/21 samples all of which had mutations in P53 as detected by SSCP analysis. The myelodysplastic syndrome (MDS) is a clonal disorder of the haemopoietic stem cells which provides an excellent model of leukaemogenesis. Samples representing all five subtypes of MDS were examined for P53 mutations by SSCP analysis. Shifts were found in $12 / 28$ subjects.

\section{Common mechanism of tumourigenesis in five types of von Hippel-Lindau disease neoplasms}

E R MAHER, P CROSSEY, K FOSTER, F M RICHARDS, E BENTLEY, $M$ PHIPPS, F LATIF, M LERMAN, B ZBAR, J R W YATES,

N A AFFARA,

M A FERGUSON-SMITH

Cambridge University Department of Pathology and Laboratory of Immunobiology, National Cancer Institute, Frederick, USA.

Von Hippel-Lindau (VHL) disease is an 
autosomal dominant familial cancer syndrome with variable expression. The most frequent complications are retinal and cerebellar haemangioblastomas, renal cell carcinoma, and phaeochromocytoma, but more than 20 different tumours have been suggested to be associated with VHL disease. The VHL disease gene has been mapped telomeric to $R A F 1$ in chromosome $3 \mathrm{p} 25$ p26, and there is statistical and molecular evidence to suggest that the VHL disease gene functions as a tumour suppressor gene. However, this concept has recently been questioned. We have analysed 21 paired tumour:blood DNA samples for evidence of loss of heterozygosity (LOH) for chromosome $3 \mathrm{p}$ markers. $\mathrm{LOH}$ was detected in five tumour types: renal cell carcinoma $(2 / 11)$, cerebellar haemangioblastoma (1/8), phaeochromocytoma (1/1), choroid plexus papilloma (1/1), and pancreatic tumour (1/1). Chromosome $3 p$ allele loss has not previously been reported in VHL associated choroid plexus papilloma and pancreatic tumour. These results suggest that there is a common mechanism of tumourigenesis in VHL disease tumours. Our results are consistent with the VHL disease gene functioning as a tumour suppressor gene $(\mathrm{LOH}$ always included the region of the VHL disease locus), but chromosome $3 p$ allele loss was not restricted to 3 p25-p26 and we cannot exclude a possible role of other chromosome $3 p$ tumour suppressor genes in the pathogenesis of VHL tumours.

\section{Early experience in preclinical diagnosis of familial adenomatous polyposis (FAP) in Wales}

\section{J SAMPSON, L HARVEY, J MYRING,} I FENTON, A WILLIAMS

\section{Institute of Medical Genetics, Cardiff.}

Thirty-three clinically normal at risk members of families with FAP have completed the Cardiff DNA diagnostic programme. Pedigree risks were modified using age of onset data in 21 subjects who had already been screened by sigmoidoscopy and in 12 the prior risk was $50 \%$. Flanking marker (Pi227, C11p11, ECB27, and YN5.48) and intragenic polymorphism studies (FB54D and the exon 11 RsaI polymorphism) reduced the risk of gene carriage to $<1 \%$ in 10 subjects. Nine of these wished to continue sigmoidoscopic screening (though on a less frequent basis) and one chose not to be screened again. Using extragenic markers we noted risk instability in one pedigree; a risk of $5.4 \%$ in one subject was revised to $38 \%$ when two cousins with unknown disease status were typed. Pedigree structure in FAP may predispose to risk instability, the poor prognosis in previous generations frequently leads to phase being unknown, and this problem is compounded by age dependent penetrance. Caution should be exercised before modifying accepted bowel screening protocols on the basis of studies with linked markers.

\section{Germline rearrangement at the $A P C$ locus detected by PFGE}

\section{SIMON GAYTHER*, KIRAN \\ GULATI*, PAMELA CHAPMAN $\dagger$ JOHN BURN $\dagger$, JOY DELHANTY*}

*Galton Laboratory, Dept Genetics $\mathcal{E}$ Biometry, University College London. $\uparrow$ Div of Human Genetics, University of Newcastle-upon-Tyne.

The autosomal dominant premalignant condition, adenomatous polyposis coli (APC), is caused by mutation or deletion of a gene which maps to chromosome 5q22. Although analysis of small, nested, molecular deletions in affected patients was instrumental in the isolation of the gene, almost all germline mutations detected so far are point mutations or 1 or $2 \mathrm{bp}$ deletions. Previously the gene MCC (mutated in colon cancer), situated at $5 \mathrm{q} 21$ and $150 \mathrm{~kb}$ proximal to $A P C$, had been considered a candidate familial polyposi gene by virtue of its high levels of somatically acquired mutations in sporadic colorectal carcinomas. We chose to investigate the nature of the germline mutation in one APC family with a severe phenotype: early onset of disease and the occurrence of multiple primary cancers. Pulsed field gel electrophoresis of an affected family member has been used to show gross rearrangement around the $A P C$ locus. The three rare cutting enzymes, MluI, NotI, and SalI, were used in single and double digests of normal and patient blood lymphocytes and probed with cDNAs encompassing the APC and MCC genes. Preliminary data show additional aberrant sized bands in the patient when compared with normal blood lymphocyte DNA. These appear to represent a rearrangement of the locus on one homologue. We propose that this rearrangement represents breakage and inversion of at least $150 \mathrm{~kb}$ of DNA close to the $A P C$ locus.

Two cases of $5 q$ deletions in subjects with familial adenomatous polyposis: possible link with Caroli's disease and Beale's syndrome

\section{A S COONAR, P J V HANSON, $S$ COTTRELL, P N SCRIVEN, T JONES, P R HAWLEY,} M L WILKINSON, S V HODGSON

Dept of Medical $\mathbb{E}$ Molecular Genetics $\mathcal{E}$ Gastroenterology, UMDS, Guy's Campas, and St Mark's Hospital, London.

Two cases of subjects with deletions of chromosome 5q are reported. Both are affected with familial adenomatous polyposis (FAP) and mild mental retardation. In both cases, the colon only had macroscopic polyposis in the proximal colon in adult life (in their thirties), although microscopic adenomatosis was shown on histological examination in the more distal colon, with occasional single polyps. Other features of FAP in both subjects included dermoid cysts and congenital hypertrophy of the retinal pigment epithelium (CHRPE). One of the subjects (case 1) has gastroduodenal polyps and desmoid tumours; the other (case 2) has a marfanoid habitus with an abnormal pectus, wasted calf muscles, clawing of the toes, and Caroli's syndrome. His deletion is cytogenetically more extensive than that in case 1 . The deletions were: proband $146, \mathrm{XX}, \operatorname{del}(5)$ (q21.3-q23.1) and proband $246, X Y, \operatorname{del}(5)$ (q15 q22.3 or 23.1). The paucity of adenomas in the left side of the colon suggests that FAP cannot always confidently be excluded by sigmoidoscopy alone. However, the expression of the disease in the colon in cases where the whole gene is deleted could be milder than in the more usual autosomal dominant cases where nonsense mutations and deletions of only a few base pairs rather than deletions of the whole gene are the rule.

\section{The dilemma of two cell populations in Fanconi anaemia}

A K HAJIANPOUR*,

M MURER-ORLANDO*, C G MATHEW*, C BENNETT*, E C GORDON-SMITH $\dagger$, C R TILEY $\ddagger$, MBOBROW*

*Division of Medical $\mathbb{E}$ Molecular Genetics, UMDS, Guy's Hospital, London.

†Department of Haematology, St George's

Hospital Medical School, London.

$\ddagger$ Leukaemia Unit, Royal Marsden Hospital, Sutton, Surrey.

Fanconi anaemia (FA) is an autosomal recessive disorder associated with diverse clinical manifestations. The heterogeneity in the phenotypic expression, clinical course, and age of onset makes diagnosis on the basis of clinical manifestations difficult and often unreliable. FA patients are currently diagnosed by cytogenetic assay, their cells showing high levels of mutagen induced chromosomal breakage. In lymphocyte cultures most or all cells usually exhibit typical chromosomal breaks and exchanges after exposure to DNA cross linking agents such as diepoxybutane (DEB). In a series of $25 \mathrm{FA}$ patients diagnosed in our laboratory, four cases were found to have two cell populations in their PHA stimulated lymphocyte cultures. After DEB treatments only a percentage of the cells analysed $(24,36,44,50 \%)$ showed an increased breakage rate (mean breakages per cell in these four cases were $0.8,0.4,1.5,0.9$; mean breakages per aberrant cell were $4.1,1.1,2.7,1.8$ respectively). There were no consistent phenotypic manifestations common to these four patients that could suggest a correlation with the cytogenetic findings, and clinical manifestations were as diverse as in classical FA. In our experience the incidence of the type of FA having two cell populations seems to be higher than that previously reported by Auerbach: $16 \%$ compared to $10 \%$. To explain the cytogenetic findings in these FA patients we suggest the following hypotheses: (1) slower cell cycle in cells exhibiting high aberrations in vitro; (2) transfusion acquired chimerism; (3) constitutional chimerism; and (4) mosaicism produced by back mutations.

Turner's syndrome detection by MSAFP/Free $\beta$ (hCG) screening

C LAUNDON, K SPENCER, J N MACRI, P BUCHANAN 
Genecare Medical Genetics Centre, Chapel Hill, NC, USA. Oldchurch Hospital, Romford, Essex. NTD Laboratories, Carle Place, NY, USA.

We report findings using a protocol for Down's syndrome maternal serum screening which includes maternal age, AFP, and Free $\beta$ (hCG). This protocol is capable of detecting $80 \%$ of all Down's syndrome pregnancies when evaluating maternal serum before 17 weeks of gestation. Data presented here are from prospective maternal serum screening. In 11 cases presenting with increased Down's syndrome risk, amniocentesis showed nine cases of 45, $\mathrm{X}$ Turner's syndrome and two cases of $45, \mathrm{X} / 47, \mathrm{XXX}$ mosaic Turner's syndrome. A 12th case presented with both raised maternal serum AFP and Free $\beta$ (hCG). Analysis of amniotic fluid cells in this case showed 46,X,i(Xq) Turner's syndrome. These cases represent a subset of chromosomal abnormalities other than Down's syndrome that are being identified by this new screening protocol. These findings prompt further investigation into the strong association between Turner's syndrome and raised Free $\beta$ (hCG)

\section{Analysis of the expansion associated with myotonic dystrophy in various tissues from fetuses predicted to be at high risk}

\section{GAIL NORBURY*, E KIERNAN†, ANNEKE MICIAK*}

*Department of Medical Genetics, Churchill Hospital, Oxford OX3 $7 \mathrm{LJ}$. †Genetics Laboratory, Department of Biochemistry, University of Oxford, Oxford OX13QU.

DNA was extracted from various tissues of two fetuses which had been terminated because they were predicted to be at high risk for myotonic dystrophy. In both cases, the mother was clinically affected and had had a previous congenitally affected child. Prenatal diagnosis was made by analysis of the expansion status by Southern analysis and in one of the cases (case 1) linkage analysis supported the interpretation. DNA was extracted from tissues which had been carefully dissected and frozen shortly after collection. The panel of tissues in addition to cultured CVS included: heart, gonad, skin, diaphragm, brain, spleen, kidney, liver, lung, umbilical cord, placental membranes (case 1) and intestine, thigh, eye, umbilical cord, placental membranes (case 2). The state of the expansion was investigated both by Southern analysis using the probe GB2.2 and by PCR in which the products were visualised both by ethidium bromide staining and probing with 32P-(CTG)10. DNA extracted from the kidney, lung, liver, intestine, and placental membranes was only suitable for analysis by PCR. All 17 tissues appeared to indicate that there was no detectable difference in expansion status between tissues within the subject. Both of these cases show large expansions (over $4.5 \mathrm{~kb}$ ). It thus appears that, at least in these cases which may represent an extreme state of amplification, tissue specific differences may not exist or are too small to be detectable under the conditions of this analysis.

\section{Analysis of the unstable CTG repeat in myotonic dystrophy}

\section{A-M DIFFER, M BOBROW, C MATHEW}

Division of Medical $\mathcal{E}$ Molecular Genetics, UMDS, Guy's Campus, London SE1 9RT.

We have investigated the length of the repeat in $29 \mathrm{DM}$ families by PCR amplification and analysis of the product on polyacrylamide sequencing gels. In unaffected subjects (controls or spouses of DM patients) 26 of 31 $(84 \%)$ were heterozygous for the number of CTG repeats (range 5 to 30 repeats). In clinically affected subjects, 41 of 47 had only one discernible allele on the PCR assay, two had an allele in the normal range and a diffuse high molecular weight band, and four were heterozygous for alleles within the normal range. Repeat sampling and clinical reassessment of the four affected subjects with a 'normal' pattern is in progress. We tested 25 subjects at risk for DM, of whom 17 had a normal pattern, three had one normal allele and a high molecular weight diffuse band, and four had only one allele. One subject, the asymptomatic father of an affected female, had one normal allele and one allele with 43 repeats. A comparative analysis of these data with those obtained on the same samples by Southern blotting is in progress to assess whether PCR analysis can replace blotting as an initial and more sensitive screen for the DM mutation.

\section{$X$ linkage in boomerang dysplasia}

\section{S SLANEY, P BOYD, H FIRTH}

Department of Medical Genetics, Churchill Hospital, Headington, Oxford $O X 37 \mathrm{LF}$.

Boomerang dysplasia is a rare form of lethal short limbed dwarfism. Four reports of male infants with the distinctive skeletal anomalies, including boomerang shaped long bones in the lower limbs, led to the suggestion of $\mathrm{X}$ linked recessive inheritance. We report two affected males in consecutive generations from the same family. A 25 year old woman presented after her first pregnancy which had resulted in a neonatal death at 33 weeks' gestation of a male baby with multiple congenital anomalies consistent with boomerang dysplasia. The mother's younger brother was born at 30 weeks' gestation and died shortly after birth with almost identical abnormalities, also fulfilling the diagnostic criteria for boomerang dysplasia. This report supports an $\mathrm{X}$ linked recessive mode of inheritance.

\section{The Martin Bell family revisited}

T HOMFRAY*, M A PATTON* ROHAN TAYLOR*, ELLA WRIGHT†

*Department of Genetics, St George's Hospital Medical School, London. + Lifecare NHS Trust, Caterham, Surrey.

In 1943, Martin and Bell reported a family with seven mentally retarded male first cousins whose mothers were sisters. Members of this family have been residing in an institution since that time. In 1978 they were cyto- genetically tested for the fragile $\mathrm{X}$ syndrome and found to be positive. Following publication of the cloning of the FMR1 gene, we returned to the institution to test any remaining members with DNA probes. Two out of the original seven members were still resident and one other had recently died. Blood was taken from one of these two men. Previous cytogenetic analysis had shown $20 \%$ fragile $X$ positive cells. Repeat analysis showed only $1 \%$. In our laboratory this is not considered a significant result. DNA analysis using probe OX1.9 showed a clear band of $7 \mathrm{~kb}$ and an absent $5 \mathrm{~kb}$ band. This confirms that the Martin Bell family does indeed have fragile $X$ syndrome and supports previous reports of a decrease in cytogenetic expression with increasing age.

\section{Fragile $X$ syndrome families in the west of Scotland}

\section{J S PATERSON, J M CONNOR}

Duncan Guthrie Institute of Medical Genetics, Glasgow.

Families with fragile $\mathrm{X}$ syndrome have been extensively studied in our area, previously by linkage analysis and cytogenetics and now with one of the new gene probes (OX1.9). We have 49 west of Scotland families on our register from a population of approximately 3 million. There are at least 80 affected males known, giving a minimum prevalence of 1 in 18750 males. There are 12 affected females, giving a prevalence of 1 in 125000 . However, since current estimates of the true frequency of affected males is 1 in 1250 , and affected females is 1 in 2000 (with a gene frequency of 1 in 850), there are clearly many undiagnosed cases of mentally handicapped persons with fragile $X$ syndrome, in particular among affected females. Geographical distribution also indicates uneven ascertainment. Increased ascertainment can only come through educating other professionals of the need for testing all subjects with unexplained mental handicap. Unusual results so far among west of Scotland pedigrees include one family with both normal and handicapped males cytogenetically fragile $\mathrm{X}$ positive, but normal on probing with OX1.9, and one family with a cytogenetic and molecular fragile $\mathrm{X}$ positive male, but a mother apparently normal on both tests.

\section{A clinical and genetic study of incontinentia pigmenti}

\section{S J LANDY, D DONNAI, A P READ}

Regional Genetic Service, St Mary's Hospital, Manchester M13 0FH.

IP is a rare $\mathrm{X}$ linked dominant condition with male lethality. Present genetic counselling is based on the analysis by Carney (1976) of 464 references. He found significant complications in $80 \%$ of cases and notable CNS disease in $30 \%$. We suspect that this represents biased ascertainment. Using strict diagnostic criteria 111 subjects ( 85 familial and 26 sporadic) were included in our study. Over $90 \%$ had a blistering rash within the first two months, over $90 \%$ had other ectodermal features, up to $30 \%$ had ocular involvement, but overall less than $10 \%$ had CNS disease. The incidence of severe mental 
retardation in familial cases was 3\% compared to $15 \%$ in the sporadic cases. Chromosomal rearrangements were found in two sporadic cases, with mosaicism in one of these, but neither involved the $\mathrm{X}$ chromosome. Linkage analysis using ST14 and F8C in six families supports linkage to Xq28. We suggest that our figures may be more accurate for genetic counselling.

\section{Congenital skull defect and recurrent abdominal desmoids: a variant of familial adenomatous polyposis?}

\section{DE SILVA*, J C S DEAN*, I GUNN $\dagger$,} N HAITES*

*Medical Genetics, Aberdeen. †Dr Gray's Hospital, Elgin.

The proband was born at term with a large skull defect which was repaired. Her parents noted that she had poor enamel deposition of her milk teeth but no other cutaneous problems. Growth and development were normal At the age of 16 years she developed a desmoid tumour of the transverse mesentery which was surgically treated. Two years later another desmoid arising from the greater omentum was also surgically treated. Two colonoscopies performed (at the age of 16 and 18 years) were normal. She has no CHRPEs (congenital hypertrophy of the retinal pigment epithelium) or jaw osteomas. There is no family history of FAP but her grandmother was noted to have a few rectal polyps (tubulovillous adenoma) at the age of 78 years. The occurrence of desmoid tumours before the development of polyps has been reported in one pedigree where a 1 year old infant had this in association with a hepatoblastoma. Skull osteomas have also been reported frequently but few if any give rise to skull defects. The significance of her grandmother's diagnosis is uncertain but it raises the possibility that a germline mutation of the APC gene is responsible for this association in our patient.

\section{The scleroatrophic syndrome of Huriez}

\section{PE JARDINE*, P W LUNT*, G KAVANAGH $\dagger$}

*Clinical Genetics Unit, Institute of Child Health, Bristol. †Dept of Dermatology, Bristol Royal Infirmary.

Huriez (1968) described 44 subjects in three families with a dominant condition characterised by palmoplantar scleroatrophy, keratoderma, and nail hypoplasia. Skin and bowel cancer was frequent. A further two families have been described in French publications. Linkage was suggested to $M N S$ s (4q28-q31) lod score 4.2 at $\theta=0.05$. In connection with a study of dysmorphic syndromes on $4 \mathrm{q}$ we have examined a family from Britain with this condition. Ten subjects were affected in three generations. Clinical features were dry, smooth, palmar and plantar skin, hyperkeratosis predominantly over pressure areas, nail dystrophy, small hands and feet, flexion contractures of the fifth finger, and a pinched nose with telangiectases. The hair and teeth were nor- mal. Two further subjects, now dead, developed squamous cell carcinomas in areas of affected skin, at ages 22 and 45 respectively.

\section{Cone-rod dystrophy associated with subretinal \\ neovascularisation and gingival dystrophy}

\section{K EVANS, A FRYER, \\ J DUVALL-YOUNG}

Royal Liverpool University Hospital, Prescot Street, Liverpool.

We describe three generations of a five generation pedigree totalling 38 patients. A form of cone-rod dystrophy was diagnosed with loss of acuity followed by progressive electroretinography changes and field loss with night blindness in later life. The inheritance pattern was autosomal dominant. In addition, most affected subjects (11 out of 17) were noted to have frontal gingival atrophy with canine tooth loss by 30 years of age. All affected subjects seemed to develop subretinal neovascularisation at both maculae by 31 to 39 years of age causing aggravated acuity loss. The combination of these three pathologies together has not previously been described, although other retinal dystrophies have been complicated by subretinal neovascularisation and cone-rod dystrophy with dental ameloger:esis imperfecta.

\section{$X$ inactivation studies in adrenoleucodystrophy}

\section{E WATKISS, S BUNDEY, T WEBB}

Department of Clinical Genetics, Birmingham Maternity Hospital, Birmingham B15 2TG.

Adrenoleucodystrophy (ALD) is an X linked progressive neurological disorder, characterised by demyelination of the central nervous system and adrenal insufficiency. Manifestation of the disease, in the form of a spastic paraplegia, sometimes occurs in female carriers. We decided to investigate whether skewed $\mathrm{X}$ inactivation might account for manifestation in females. We used the probe M27 $\beta$ and the enzymes Pst I MspI/HpaII on three manifesting carriers of ALD and on nine non-manifesting carriers. Of the manifesting carriers, two showed random $\mathrm{X}$ inactivation and one was uninformative. Of the non-manifesting carriers, four showed skewed $\mathrm{X}$ inactivation. There was no association of skewness with age. These results suggest that skewed $\mathrm{X}$ inactivation is not a major factor in the manifestation of ALD.

\section{A search for uniparental disomy in Sotos syndrome}

\section{T COLE*, YU QI $\dagger$, K AMINU†,} M UPADHY: Y, YA $\dagger$

\section{*Birmingham, $†$ Cardiff.}

Sotos syndrome (SS) is an overgrowth syndrome associated with developmental delay. The aetiology remains uncertain. In our study of 40 patients with SS there are no pedigrees supporting either $A D$ or $A R$ in- heritance, although paternal age is significantly raised (observed 31.5 , expected 28.6 ; $0.02>p>0.01$ ). We report preliminary results of a systematic search for uniparental disomy (UPD) in SS, initially focused on five candidate regions, $3 \mathrm{p} 21,6 \mathrm{p} 21,4 \mathrm{p}, 2 \mathrm{p}$, and 11p15. The first two regions are the breakpoints in a patient with SS and a de novo reciprocal translocation. The third and fourth were considered following our finding of a mosaic translocation involving $2 p$ and $4 \mathrm{p}$. Finally $11 \mathrm{p} 15$ was investigated because of its association with the overgrowth disorder Beckwith-Wiedemann syndrome. Twenty-four nuclear families have been studied by Southern blot hybridisation with a set of diallelic and variable number tandem repeat (VNTR markers) DNA probes. These included $\mathrm{H} 3 \mathrm{H} 2$, pEFD134.7, and pEFD64.1 on chromosome 3, pATA and pJCZ30 on chromosome $6, \mathrm{pYNH} 24$ on chromosome 2 , pMCOC14 on chromosome 4 , and $\mathrm{cH}-\mathrm{RAs} 1$ and pHINS311 on chromosome 11. To date we have not detected UPD using these markers.

Ear anomalies, clefting, and limb reduction defects: a new autosomal recessive condition?

IAN A GLASS*,

JAN WALFORD-MOORE*,

STEPHEN CHAPMAN†, PETER A FARNDON*

*Genetics Unit, Birmingham Maternity

Hospital, Birmingham. $\uparrow$ Radiology Department, Birmingham Children's

Hospital, Birmingham.

We present a pair of sibs of healthy unrelated parents with an interesting range of clinical manifestations. The male presented at birth, after a normal pregnancy, with extreme macrocephaly owing to multilocular porencephaly. His karyotype was normal. He was also noted to have a cleft palate and the family were counselled that this was likely to be the result of a deleterious vascular event. The second child, a female, was born after an unremarkable pregnancy and was noted to have absence of the right arm accompanied by rhizomelic shortening of the left upper limb and camptodactyly of the third finger at the PIP joint. She was observed to be dysmorphic with upward slanting external palpebral fissures, a cleft palate, hypoplastic external auditory meati, and bilateral preauricular tags. Her CT scan of the brain was normal, the karyotype was $46, \mathrm{XX}$, and premature centromeric separation of the chromosomes was not observed. On re-examination of the index case hypoplastic external auditory meati and bilateral preauricular tags were apparent but the facial structures were by now very distorted. An excess of alcohol or vitamin A intake was not a feature during either pregnancy. The sibs most likely represent inheritance of an identical autosomal recessive gene with an unusual spectrum of manifestation.

\section{Male fertility in Noonan syndrome}

M M ELSAWI*, J PRYOR $\dagger$, R JOSHI $\dagger$ M A PATTON*, G KLUFIO $\dagger$ 
*Department of Genetics, St George's Hospital, London. + Fertility and Endocrine Centre, Lister Hospital, London.

Pubertal development is often delayed in Noonan syndrome. Undescended testes (UDT) are frequently found in males with this disorder. It is unclear as to what extent this contributes to their fertility problem. Fourteen men of normal intelligence were invited to attend for an andrological history, examination, seminal test, and evaluation of plasma levels of FSH, LH, and testosterone. Eight patients attended (mean age 26.1 years). In all subjects penile function was normal, and the mean flaccid stretched length was $11 \cdot 1 \mathrm{~cm}$ (range 10 to $13 \mathrm{~cm}$ ). Two men with UDT had fathered children and had been vasectomised. In three men semen assessment showed severe impairment of fertility. The remaining three were unable to provide a sample reflecting delayed sexual maturity. Normal testicular descent had occurred in four patients and testes were of normal size (mean vol $=21 \mathrm{ml}$ ). Three of them had normal hormonal levels, while the fourth had an FSH of $30 \mathrm{IU} / 1$ (range 1 to 7) and a sperm count less than 1 million $/ \mathrm{ml}$. The other four patients had orchidopexy for UDT with a mean testicular volume of $20 \mathrm{ml}$. FSH levels were high in two of them ( 20 and $36 \cdot 1 \mathrm{IU} / 1$ ) who also had azoospermia. It seems that the problem of fertility in Noonan syndrome cannot be explained solely by the high incidence of UDT.

\section{Audiometric identification of carriers of Usher's syndrome type II}

\section{R MEREDITH*, S D G STEPHENS*, $C$ MEYER-BISH + , W REARDON $\ddagger$, K S SIRIMANNA*}

*Welsh Hearing Institute, University Hospital of Wales, Cardiff. $\dagger$ Except, 82 Rue Stanislas, Nancy, France. $\ddagger$ Institute of Medical Genetics, University Hospital of Wales, Cardiff.

Several previous attempts have been made to identify an audiometric technique for the detection of carriers of autosomal recessive hearing loss. The most promising work was with the detection of audiometric notches using sweep frequency Bekesy audiometry, but results with this technique have not been universally successful. In the present study we have tested the hearing of carriers of Usher's syndrome II, an autosomal recessively inherited form of syndromic deafness and retinitis pigmentosa, in four families using a new sweep frequency technique called Audioscan. With this technique we found audiometric notches in the frequency range of 500 to $3000 \mathrm{~Hz}$ in all six obligate carriers tested and in six out of $14(42.9 \%)$ subjects with a 50 to $67 \%$ prior risk of being heterozygous for the gene. Significantly more notches were found in the obligate and possible carriers than in a control group. Based on these data, we conclude that the Audioscan technique may offer a sensitive method of detecting carriers in families with Usher's syndrome II and may be an effective adjunct to genetic counselling in families with this condition.

\section{Antenatal carrier screening for cystic fibrosis: comparative evaluation of two approaches}

Z H MIEDZYBRODZKA*†, NE HAITES* $*$, M H HALL + , A A TEMPLETON $\dagger$, T M MARTEAU $\$$, J C S DEAN*, K F KELLY I T RUSSELL $\|$

University of Aberdeen Depts of Medicine and Therapeutics*, Obstetrics and Gynaecology†, and Molecular and Cell Biology Unit |, Medical School, Foresterhill, Aberdeen AB9 2ZD. §Royal Free School of Medicine Dept of Academic Psychiatry, Hampstead, London.

We are performing a randomised trial of stepwise versus couple screening, incorporating both psychological and economic evaluation. CF carrier tests are offered at the Aberdeen Maternity Hospital antenatal clinic, with thorough counselling for both approaches. A comparative evaluation of these approaches is necessary because it has been proposed that with couple screening (1) less anxiety may be provoked, (2) screening efficiency may be less as relatives of carriers cannot be made aware of their increased risk, (3) uptake rates may be lower, and (4) financial costs may differ. To date, 920 women have been offered stepwise screening. Of these $91 \%$ chose to take the test and 30 carriers were detected. Partners of 29 carriers accepted the offer of carrier testing after counselling. One pair of carriers has been found who elected to have prenatal diagnosis. Eighty-five percent of 220 couples offered couple screening took the test. One pair of carriers has been identified; they elected to have prenatal diagnosis. Four carriers have been given a low risk result because of their partner being at low risk of being a carrier. Uptake rates of both approaches are high and not significantly different from each other. Psychological and economic factors may prove most important in determining the best method for antenatal carrier screening.

\section{A pilot population carrier screening programme for cystic} fibrosis

A SILVER*, S DEAR*, F BEARDS*, C MATHEW*, H BEKKER $\dagger$, T MARTEAU $\dagger$, G DENNISS $\ddagger$, M MODELL $\ddagger$, M BOBROW*

*Division of Medical and Molecular Genetics, United Medical and Dental Schools, Guy's Hospital, London. $\dagger$ Academic Dept of Psychiatry, Royal Free Hospital School of Medicine, London. $\ddagger$ Kentish Town Health Centre, London.

A pilot population screening programme for cystic fibrosis has been carried out in a primary health care centre to evaluate uptake rates for screening and to assess laboratory aspects. Thirty-four carriers were identified in 1040 subjects who were screened for the four mutations detected by the ARMS multiplex assay (Cellmark Diagnostics). Retesting of samples with conventional assays for these mutations showed no false negatives and one false positive result in the ARMS assay. This was a non-pathological sequence change $(621+3 A>G)$ which resulted in amplification from the mutant ARMS primer. The ARMS assay proved to be a rapid and reliable test for the presence of the four mutations. Screening uptake rates were very dependent on the method of approach used, with the active opportunistic approach being the most productive. Analysis of $172 \mathrm{CF}$ patients in the South East Thames Region for $17 \mathrm{CF}$ mutations accounted for $80 \%$ of all $\mathrm{CF}$ chromosomes in this region.

\section{An unusual cystic fibrosis family}

HR DAVIDSON*, J Y PATON $†$, B H R STACK $\ddagger$ J A H FORREST\&, J LAMBERT*, A E SHRIMPTON

${ }^{*}$ Department of Medical Genetics and $\dagger$ Department of Child Health, Royal Hospital for Sick Children, Yorkhill, Glasgow G3 8Sf. $\ddagger$ Western Infirmary Dumbarton Road, Glasgow. §Stobhill General Hospital, Balornock Road, Glasgow. \|Department of Human Genetics, Western General Hospital, Crewe Road, Edinburgh.

We report clinical and molecular results on a family with $\mathrm{CF}$ in four members of two generations. They show a wide variation in phenotype and an uncommon mutation inherited from both sides of the family which nearly led to our failure to recognise the adults as being affected. The proband was an infant with congenital heart defect (Fallot's tetralogy) requiring shunting, who had recurrent severe respiratory infections with Pseudomonas and failure to thrive out of keeping with the severity of her heart lesion. Sweat tests gave equivocal results and CF gene mutation analysis showed her to carry both $\Delta \mathrm{F} 508$ and $\mathrm{R} 117 \mathrm{H}$. Analysis of the immediate family showed that the healthy father carried $\mathrm{R} 117 \mathrm{H}$, the mother carried $\Delta \mathrm{F} 508$, and the 7 year old brother, who had no bowel symptoms and a single attack of 'croup', carried both $\mathrm{R} 117 \mathrm{H}$ and $\Delta \mathrm{F} 508$. However, although the 30 year old mother was not related to her husband and appeared well, it emerged that she had a history of chest symptoms since her teens diagnosed as bronchopulmonary aspergillosis and further analysis of her DNA showed her to carry $\mathrm{R} 117 \mathrm{H}$ in addition to $\Delta \mathrm{F} 508$. With this result, further discussion indicated that her 24 year old brother had a lifelong history of mild 'asthma' and a two year history of loose bowel motions and abdominal pain diagnosed as Crohn's disease. He also carries $\Delta \mathrm{F} 508$ and $\mathrm{R} 117 \mathrm{H}$. Thus the clinical spectrum of 'cystic fibrosis' continues to enlarge, needing a greater index of suspicion in both paediatricians and now in adult physicians for possible cases. As sweat tests may be equivocal in these patients and are more difficult to interpret in adults, greater reliance may be placed on the genotype for diagnosis with obvious implications for the DNA laboratories.

\section{Cystic fibrosis in Grampian: a population study}

ZOFIA MIEDZYBRODZKA* $\dagger$, JOHN DEAN*, GEORGE RUSSELL JAMES FRIEND*, KEVIN KELLY§, NEVA HAITES*\& 
University of Aberdeen Departments of Medicine and Therapeutics*, Obstetrics and Gynaecology $\dagger$, Child Health $\ddagger$, and Molecular and Cell Biology§, Medical School, Foresterhill, Aberdeen AB9 2ZD.

We have ascertained cases of CF in Grampian region, north-east Scotland, from 1960. The regional incidence was calculated to be $1 / 2260$ and the carrier frequency $1 / 24$. The estimated point prevalence on 1.1 .89 was $1 /$ 7100 (correcting for cases not yet diagnosed); this is higher than that reported for Britain. One hundred and nineteen of the $120 \mathrm{CF}$ chromosomes known within Grampian on the prevalence date were analysed. A mutation was detected in $94 \%(82.1 \% \Delta \mathrm{F} 508$, $6.8 \% \quad$ G551D, $\quad 1.7 \% \quad$ G542X, $3.4 \%$ $621+1, \mathrm{G}-\mathrm{T}, \quad 1717-1, \mathrm{G}-\mathrm{A}, \quad \mathrm{R} 553 \mathrm{X}, \quad$ or $\Delta \mathrm{I} 507)$. No mutation was detected on seven chromosomes despite additional testing for R560T and R117H. The prevalence of $\Delta F 508(81 \%)$ and other identifiable mutations $(94 \%)$ is significantly higher than that previously published $(71 \% \Delta \mathrm{F} 508,84 \%$ all mutations) for a mainly southern Scottish population. These findings have local implications for the efficacy of carrier screening and the usefulness of DNA testing in cases where the diagnosis of CF is in doubt.

\section{Relative risk and risky relatives}

\section{R N CURNOW*, R BUTLER†,} J L WHITTAKER †

*Department of Applied Statistics, Reading University. $\dagger$ Regional Molecular Genetics Laboratory, RLCH Alder Hey, Liverpool.

Cystic fibrosis $(\mathrm{CF})$ is a recessive disorder in which some, but not all, mutations can be identified. Thus, consultands who test negative are at risk of carrying an undetectable mutation. This risk can be calculated by using Bayes' theorem in conjunction with the results of mutation analyses from the consultand and their relatives. The tabulated results of these calculations provide a simple method for obtaining accurate risk values for a consultand who tests negative in CF gene mutation analyses. A computer program to calculate the probabilities for diseases with any given incidence and proportion of detectable mutations is available from the first author.

\section{Reproductive behaviour after a second trimester termination of pregnancy}

\section{C A WHITE-VAN MOURIK*, J M CONNOR*,}

\section{A FERGUSON-SMITH $\dagger$}

*Duncan Guthrie Institute of Medical Genetics, Yorkhill Hospitals, Glasgow G3 8Sf. †Department of Pathology, University of Cambridge, Tennis Court Road, Cambridge.

Eighty-four couples were interviewed two years after a second trimester termination of pregnancy for fetal abnormality (TOP for FA). The aims were to assess their reproductive behaviour and to identify those whose desire for children conflicted with their fear of further fetal abnormalities and the personal decisions that would again con- front them. The design of the study allowed for direct comparison with a similar Dutch study. After the TOP for FA, of the total group $53 \%$ had a further pregnancy (all accepted prenatal diagnosis), $29 \%$ were trying to conceive, and $4 \%$ decided against further reproduction and were content with this decision. Reproductive conflict was observed in $14 \%$ of the couples. This was less than the $42 \%$ ( 46 of 110 ) observed in the Dutch study. Women over 35 years of age and those who had experienced a second fetal abnormality but who had at least one living child were over-represented in those experiencing reproductive conflict. There was no correlation between suffering reproductive conflict and religious beliefs or level of genetic risk.

\section{Ocular motor abnormalities in early Huntington's disease}

P J MORRISON* $\dagger$, J M GIBSON $\dagger$, A D COLLINS $\dagger$, N C NEVIN*

Departments of Medical Genetics* and Neurology $\dagger$, The Queen's University of Belfast, Northern Ireland.

Saccadic abnormalities described in Huntington's disease (HD) include fixation instability, slow saccades, and impaired frontal lobe guided saccadic tasks. We systematically examined a range of five saccadic paradigms in patients with early HD. A total of 85 families was available, following virtually complete ascertainment in the Northern Ireland population. There were 95 living affected patients and $25(26 \%)$ had early signs of HD. Eighteen $(72 \%)$ of the subjects with early HD were tested with saccadic paradigms: the age range was 28 to 68 (mean 47) Two failed owing to excessive blinking artefact. Of the 16 successful studies, 15 had quantitatively abnormal results: all showed abnormal antisaccades and abnormal remembered saccades, six showed abnormal predictive saccades, five showed slowing of saccades, one showed abnormal accuracy, and none showed prolonged latency. More than one saccadic paradigm should be used to detect early ocular motor abnormality in HD. Systematic ocular movement studies may produce early clues to the diagnosis of HD

\section{Heterozygote frequency,} mutation rate, fertility, and genetic fitness in the N Ireland Huntington's disease population

\section{P J MORRISON, N C NEVIN}

\section{Department of Medical Genetics, Belfast} City Hospital, Belfast BT97AB.

The epidemiology of Huntington's disease (HD) in the Northern Ireland (NI) population has been extensively studied. Following virtually complete ascertainment, estimates of the heterozygote frequency, direct and indirect mutation rates, fertility, and genetic fitness (W) of the population were made for 1 April 1991, the date of the decennial census in NI. The estimates were found to be significantly different from the small number of similar published studies on HD. The heterozygote frequency was calculated by a number of methods, the more reliable estimates giving values between 10 and $11 \times 10^{-5}$. The direct and indirect mutation rates were $0.32 \times 10^{-6}$ and $1.05 \times 10^{-6}$ respectively. Values of $W$ for affected (c) and at risk (n) populations were $\mathrm{Wc}=1.19$ and $W n=0.97$. The genetic fitness was increased for the Wc population but decreased for the Wn population. This is consistent with the low heterozygote frequency (which is lower than comparable published values) in the NI HD population. It appears that at risk patients have actively limited their family size. Factors responsible for this lowered Wn value and low heterozygote frequency include, among others, the fear of developing the disease and genetic counselling of families.

Prevalence and incidence of
Duchenne (DMD) and Becker (BMD) muscular dystrophies in Slovenia

\section{B PETERLIN*, J ZIDAR†, M MEZNARIC,+ N ZUPANCIC $\ddagger$, CBOILEAU§}

*Division of Medical Genetics UGK, UKC Ljubljana. $\dagger$ Institute of Clinical Neurophysiology, UKC Ljubljana. $\ddagger$ University Paediatric Clinics, UKC Ljubljana. §INSERM U73, Paris.

The prevalence and incidence of DMD and BMD were measured in the state of Slovenia (population of 1999477 in 1990). Patients were identified from the national register of neuromuscular disorders and from the records of University Paediatric Clinics and Division of Medical Genetics, Ljubljana. Besides the usual diagnostic and clinical criteria we used deletion screening in the dystrophin gene as an additional diagnostic test. By this means three BMD patients were identified in a group of 14 patients with inconclusive clinical diagnosis. Thirty-six DMD and 15 BMD patients were ascertained in 1990 , giving minimum prevalence rates of $1.8 / 100000$ and $0 \cdot 75 / 100000$ respectively. The cumulative birth incidence (from 1970 to 1985) for DMD was $16 \cdot 7 / 100000$ compared to $4 \cdot 8$ / 100000 for BMD. Prevalence and incidence rates evaluated in this study are comparable to the published estimates worldwide, but suggest that the incidence of BMD versus $\mathrm{DMD}$ is higher than previously thought.

\section{The Emilia Romagna birth defects register: goals and accomplishments}

E CALZOLARI*, G P GARANI $S$ VOLPATO $\dagger$, G COCCHI $\ddagger$, C MAGNANI\&, M MILAN*, IMER WORKING GROUP

1st Genetica Medica Ferrara*, 1st Pediatria Ferrara†, 1st Pediatria Preventiva e Neonatologia Bologna $\ddagger$, 1st Puericultura e Medicina Neonatale Parma§, Italy.

The Emilia Romagna Register for congenital malformations was established in 1978. During the study period, among 242696 births with a regional coverage of $90 \%, 4610$ cases $(1.9 \%)$ were detected. No cluster in time or space could be demonstrated. In the years 
1981 to 1990,870 babies with multiple anomalies were detected. Among them, there were 390 cases with chromosomal anomalies $(1.9 \times 1000), 90$ with monogenic conditions, and 26 with an environmentally caused condition $(0.1 \times 1000)$. In 105 cases $(0.5 \times 1000)$ a known association or sequence was identified. Particular attention was given to the identification of specific syndromes with high recurrence risk (144 cases, $4.7 \%$ ) and genetic counselling was offered.

\section{Homozygosity mapping of autosomal recessive disorders and complex consanguinity}

R F MUELLER*, P STOCKWELL †, M DENTON + , C J CHAPMAN + , R J M GARDNER $\$$

*Dept of Clinical Genetics, The General Infirmary at Leeds. $\dagger$ Dept of Biochemistry, University of Otago. $\ddagger$ Dept of Paediatrics, University of Auckland. §Dept of Paediatrics, University of Otago.

Mathematical analyses of the power of nuclear families for autosomal recessive disorders have shown that in order to have a high likelihood of showing linkage in gene mapping studies inordinate numbers of families, preferably with multiple affected sibs, are required. Use of homozygosity mapping with affected offspring of first cousins has been advocated as far fewer families are needed to have the same likelihood of showing linkage. Collection of affected offspring for linkage studies of ostensible first cousin matings from certain ethnic groups in which consanguineous marriage is common often shows the consanguinity to be much more complex than at first enquiry. Modelling the more common complex consanguineous pedigree structures encountered shows that previous inbreeding patterns, polymorphic marker loci, and disease allele frequencies and possible locus heterogeneity affect the potential power of these families in linkage studies.

\section{Flanking markers for the gene for the Gorlin syndrome}

\section{HARDY*, R G DEL MASTRO*,} M TAYLOR,+ D G R EVANS + $M$ W KILPATRICK*, PA FARNDON*

*Department of Clinical Genetics, Birmingham Maternity Hospital. $\dagger$ Department of Cancer Studies, Birmingham University. $\ddagger$ Department of Medical Genetics, Manchester.

The Gorlin (naevoid basal cell carcinoma) syndrome is an autosomal disorder charac terised by multiple naevoid basal cell carcinomas, recurrent odontogenic keratocysts, skeletal anomalies, intracranial calcification and developmental malformations. As part of a continuing clinical study of over 70 affected patients, we presented linkage data localising the gene to $9 \mathrm{q} 22.3-\mathrm{q} 31$ in nine families. further four families have been studied and there continues to be no evidence of locus heterogeneity in our families although there is variability of clinical signs and symptoms within and between families. $Z \max$ is 7.70 with $D 9 S 127$ at $\theta=0.05$. Recombinants place the gene between $D 9 S 12$ and $D 9 S 127$.

\section{A linkage study of $\mathrm{X}$ linked Charcot-Marie Tooth disease (CMTX) using highly informative loci}

$S$ COCHRANE*, N FAIRWEATHER ${ }^{*} \dagger$, K KELLY*, A JOHNSTON*, A MONACO + , NHAITES*

*Medical Genetics, University of Aberdeen, Foresterhill, Aberdeen. $\dagger$ Institute of Molecular Medicine, fohn Radcliffe Hospital, University of Oxford, Oxford.

Previous studies of CMTX have shown linkage of the disease to loci between the centromere and Xq13. We are studying a number of $\mathrm{X}$ linked families, including a large Scottish family and three smaller British families. These four families were studied using four highly polymorphic probes: M27ß (EcoR digests) Xp11.22; HAR (PCR primers and $D X S 453$ (PCR primers) both within interva 7, Xq11.2-q13.1; PGK1 (Pst I/XbaI digests) $\mathrm{Xq13.3}$. $\mathrm{Zmax}$ for locus $\mathrm{M} 27 \beta$ is 7.42 at $\theta=0.10 ; H A R 8.56$ at $\theta=0.05 ; D X S 4537.32$ at $\theta=0.00 ; P G K 15.05$ at $\theta=0.00$. As can be seen these markers are tightly linked to the disease locus. From these results the most likely position of the disease is distal to $H A R$ and proximal to $D X S 453$. However, there is limited information on this area owing to lack of crossovers within these families.

\section{Linkage studies in $\mathrm{X}$ linked Emery-Dreifuss muscular dystrophy: a new microsatellite marker localises a key recombinant}

\section{J P WARNER*, J R W YATES*,} J A SMITH*,

I HAUSMANOWA-PETRUSEWICZ $\dagger$, J ZAREMBA $\ddagger$ J BORKOWSKA $\dagger$, J-P AZULAY§, C G COLE $\|$, V DUBOWITZ $\uparrow$, L MERLIN**, NA AFFARA*

MA FERGUSON-SMITH*

*University of Cambridge. $\dagger$ Medical Academy and $\ddagger$ Psychoneurological Institute, Warsaw. \$CHU Timone, Marseille, France. United Medical and Dental Schools, Guy's Campus, London. $\uparrow$ Royal Postgraduate Medical School, London. **Istituto Ortopedico Rizzoli, Bologna, Italy.

$\mathrm{X}$ linked Emery-Dreifuss muscular dystrophy (EMD) is a rare disorder characterised by early contractures, slowly progressive muscle wasting and weakness (initially humeroperoneal), and cardiomyopathy with conduction defects and a risk of sudden death, mapped to Xq28. We have studied eight families (including three not previously published) with DNA markers from distal $\mathrm{Xq}$. Our data confirm that $E M D$ is very close to the factor VIII coagulant gene locus $(F 8 C)$ with a maximum lod score of 7.86 at 0.03 recombination. Three recombinants support $D X S 52 / D X S 15$ as proximal flanking markers and one recombinant supports $F 8 C$ as a distal flanking marker. Multipoint analysis incorporating published data confirms placement of EMD distal to $D X S 52 / D X S 15$ with the most likely location between the red/green cone pigment genes $(R G C P)$ and $F 8 C$. The physical distance from $R G C P$ to $F 8 C$ is about $800 \mathrm{~kb}$ and we have subcloned YACs from this region into cosmids and screened for microsatellite markers to characterise the flanking recombinants. This has identified a polymorphic CA repeat which is informative in the key recombinant between $E M D$ and $F 8 C$ providing localisation of this crossover to within $100 \mathrm{~kb}$ of the $3^{\prime}$ end of the factor VIII gene.

\section{Genetic localisation of RP2 type of $\mathrm{X}$ linked retinitis pigmentosa}

M A ALDRED*, M DEMPSTER*, M JAY,$+ P W$ TEAGUE* A D CAROTHERS*, L STRAIN D J H BROCK,$S$ BUNDEY§, B JAY $\dagger$, A C BIRD $\dagger, s$ S BHATTACHARYA $\|$ A F WRIGHT*

*MRC Human Genetics Unit, Western General Hospital, Edinburgh. + Dept of Clinical Ophthalmology, Moorfields Eye Hospital, London. $\ddagger$ Human Genetics Unit, University of Edinburgh. \$Clinical Genetics Unit, Birmingham Maternity Hospital, Birmingham. ||Human Genetics Unit,

University of Newcastle-upon-Tyne.

Heterogeneity analysis has been carried out on $37 \mathrm{X}$ linked retinitis pigmentosa families. Seven families were identified with $>70 \%$ probability of being RP2 type. Six point linkage analysis was carried out on this subset of families in order to localise RP2. The results show that the most likely order of loci is: tel-OTC-0.09-DXS228/DXS7/MAOA0.03-RP2-0.12-TIMP-0.03-DXS255-0.06$D X S 14$ - cen with a maximum multipoint lod score of 13.46. Locus heterogeneity causes problems in the presymptomatic diagnosis of carriers and in prenatal diagnosis In small families, the disease locus often cannót be determined. However, provided that no recombination occurs in the $R P 3$ $R P 2$ interval (about $73 \%$ of meioses), it is possible to provide accurate risks by examining markers flanking both disease loci. In one such prenatal diagnosis, the probability of error owing to an undetected double recombination event was calculated as 0.009 assuming no interference, or 0.003 allowing for interference. Finally, three families with putative X linked RP have been identified that do not show linkage to the $R P 3$ or $R P 2$ regions. Further studies are required to investigate the possibilities of another $\mathrm{X}$ linked locus or autosomal dominant RP.

Identification of a nonsense mutation in the amelogenin gene (AMELX) in a family with $X$ linked amelogenesis imperfecta (AIH1)

M J ALDRED*, P J M CRAWFORD $\dagger$, E ROBERTS*, N S T THOMAS*

*Institute of Medical Genetics, University of Wales College of Medicine, Cardiff.

$\dagger$ Department of Child Dental Health, University of Bristol Dental School and Hospital, Bristol.

A previously undocumented family with $\mathrm{X}$ 
linked amelogenesis imperfecta has been investigated. In some subjects the most noticeable defect was of enamel hypoplasia whereas in others the hypoplastic changes were subtle (and might have been overlooked on cursory examination) and the most noticeable change was of enamel colour, indicating a degree of hypomineralisation. PCR amplification and direct DNA sequencing of exons of the amelogenin (AMELX) gene has been carried out. A nonsense mutation was found in exon 5 involving a single base deletion $(\mathrm{CCCC} \rightarrow \mathrm{CCC})$ in an affected male, altering the reading frame and introducing an inappropriate TGA stop codon (an opal mutation) into the exonic sequence of the gene immediately $3^{\prime}$ of the mutation. We propose that AMELX is implicated in both the formation of enamel of normal thickness and in the normal mineralisation process.

\section{Screening for occult $Y$ mosaicism in girls with Turner's syndrome}

\section{CHU*, M D CDONALDSON*, C J H KELNAR $\dagger$, J M CONNOR $\ddagger$}

*DCH, Glasgow. $\ddagger$ Duncan Guthrie Institute, Glasgow. $†$ Child Life and Health, Edinburgh.

The percentage of mosaics in fetuses is appreciably higher than in liveborns with Turner's syndrome. This has led to the theory that most $45, \mathrm{X}$ girls are actually mosaics owing to a mitotic error in an early zygote. If the mosaicism is in a small percentage of cells, it may be missed with conventional cytogenetic analysis where only a small number of cells are analysed. Occult $Y$ mosaicism has important clinical implications because of the increased risk of gonadoblastoma. The aim of this study was to look for occult $\mathrm{Y}$ mosaicism in girls with Turner's syndrome. Fifty-two girls with Turner's syndrome with a variety of karyotypes were investigated by PCR, using a series of primers from all areas of the $Y$ chromosome. A total of five patients was found to be positive for $Y$ sequences. Two of these had 45,X/46,XY karyotypes and one was $45, X / 46, X+m$. These three were positive for all sequences analysed. The last two girls had 45,X karyotypes. One girl was positive for $Y$ centromeric sequences and is presumed to have a small fragment and the other positive for long arm material and is presumed to have a translocation. PCR is a rapid method for detecting $Y$ sequences in Turner girls and in view of the relatively high percentage found in this study we would recommend screening of all girls with a panel of $\mathrm{Y}$ specific primers.

\section{Screening for the $\mathbf{G 9 8 5}$ medium chain acyl-CoA dehydrogenase deficiency mutation in Scottish women}

\section{DUNDAR, W G LANYON, JM CONNOR}

Duncan Guthrie Institute of Medical Genetics, Glasgow.

Medium chain acyl-CoA dehydrogenase deficiency (MCAD) is a common inborn error of metabolism which results in defec- tive mitochondrial beta-oxidation of long chain fatty acids. It has been associated with sudden unexplained death in children. A point mutation changing adenine to guanine at position 985 in the MCAD cDNA sequence has been found to be a common mutation accounting for more than $90 \%$ of all disease alleles in the MCAD gene. The carrier frequency of $\mathrm{G} 985$ by DNA analysis has been reported in two studies. Blakemore et al found six heterozygotes among 410 neonates in Trent, UK (carrier frequency 1 in 68), and Matsubaru et al found 12 among 479 neonates in Birmingham (carrier frequency 1 in 40 ). We have used DNA extracted from clotted blood obtained from our alphafetoprotein screening laboratory and have used a combination of PCR with $N c o$ I restriction enzyme digests to look for the G985 mutation. We screened a total of 542 women and have found that two of them were carriers of the mutation, giving a heterozygote frequency of 1 in 271 . We conclude that the level is considerably lower than that found in other UK studies, suggesting either that MCAD is not a significant contributing factor in sudden infant death syndrome in Scotland, or that another MCAD mutation is more common in this population.

\section{Manifesting heterozygosity in Norrie's disease}

\section{R NEWBURY-ECOB*, D PLAHA $\dagger$,} I D YOUNG*, G WOODRUFF

\section{*Clinical Genetics, Nottingham. †Molecular} Genetics, Leicester. $¥$ Ophthalmology, Leicester.

A female child with a characteristic family history of Norrie's disease presented at the age of 2 with leucocoria and a retinal fold. DNA studies of her affected brother detected no deletion with L1-28 ( $D X S 7$ locus). Studies of family members with this and other markers known to be linked to the Norrie's disease locus showed that the female child, her affected brother, and an affected uncle had inherited the same grandmaternal $X$ chromosome, which was different from the $\mathrm{X}$ inherited by the unaffected uncle. Methylation sensitive $\mathrm{X}$ chromosome probes showed that in the female child there was a skewed X inactivation pattern favouring expression of the maternal X. These observations are consistent with the hypothesis that the ocular findings in this girl are the consequence of manifesting heterozygosity for Norrie's disease.

\section{Mutation analysis of fragile $X$ families}

\section{G S CROSS, A L SHARIF}

Molecular Genetics Department, City Hospital, Nottingham.

We report on our analysis of 23 families with a clinical and cytogenetic diagnosis of fragile $X$. This used the probes OX 1.9 and OX0.55 To assess the accuracy of the test, 33 likely female carriers were analysed. Full mutations or premutations were detected in all but one of these. The exception was from a family where no affected male DNA was available to confirm presence of the mutation.

\section{Early experience of fragile $X$ mutation detection in the north-east of Scotland}

C CLARK*, J C S DEAN*, K F KELLY*,
G STEPHEN*, N E HAITES*, J BRADLEY*, M FAED ${ }^{\dagger}$

* Medical School, University of Aberdeen. $\uparrow$ Medical School, University of Dundee.

The use of DNA analysis and cytogenetics has been examined in patients between the ages of 2 and 5 years referred by the local preschool development assessment centre for developmental delay. Forty-three patients have been analysed cytogenetically and using DNA probes and PCR to detect the unstable microsatellite repeat $\mathrm{p}(\mathrm{CCG}) \mathrm{n}$ at $\mathrm{Xq} 27.3$. Mutations were found in three patients $(7 \%)$ who were cytogenetically negative.

\section{DNA markers for the analysis of the Crigler Najjar syndrome,} type I

\section{N MOGHRABI, B BURCHELL, M BOXER}

Departments of Pathology and Biochemistry, Ninewells Hospital and Medical School, Dundee DD19SY.

Crigler Najiar syndrome type I (CNI) is a lethal, recessively inherited metabolic disorder characterised from birth by unconjugated hyperbilirubinaemia. Glucuronidation, essential for detoxification and excretion of bilirubin, is catalysed by two members of a family of hepatic isoenzymes, the UDP-glucuronosyl transferases (UGT-1 gene, EC 2.4.1.1.7). Several isoforms of the enzyme are encoded by a single gene with different functional specificity being achieved by the joining of unique exons which encode the amino-terminal portion of each isoform and exons which encode the common c-terminal portion. Normal levels of liver and bile bilirubin UGT activity is absent in patients with CNI and previously no prenatal diagnosis has been possible. Informative DNA markers for the UGT-1 gene have been developed and are shown to co-segregate with CNI in sibship analysis of affected families. These data confirm the autosomal recessive nature of $\mathrm{CNI}$ and identify markers for both carrier detection and prenatal diagnosis.

\section{Visualisation of microsatellite repeats by silver staining}

\section{A J WALLACE, R C MOUNTFORD, P WILLIAMSON, S C RAMSDEN}

Regional Molecular Genetics Laboratory, Dept of Medical Genetics, St Mary's Hospital, Hathersage Road, Manchester M13 OFH.

We have developed a protocol that allows the detection of microsatellite repeats non-isotopically, using silver staining. Amplified PCR products are run on $1 \mathrm{~mm}$ thick, 8 to $10 \%$ (19:1) polyacrylamide gels. Microsatellites up to $140 \mathrm{bp}$ in size are run during the day on $12 \mathrm{~cm}$ minigels, larger products are either cut down using an appropriate restric- 
tion enzyme or run overnight on $50 \mathrm{~cm}$ gels. Gel staining is a simple four step process that takes under one hour to complete and is as follows. (1) Immerse gel twice for three minutes in $10 \%$ ethanol: $0.5 \%$ acetic acid. (2) Immerse gel for 15 minutes in $0.1 \% \mathrm{AgNO}_{3}$ (this solution can be re-used several times until staining efficiency declines). (3) Rinse gel briefly twice in $\mathrm{dH}_{2} \mathrm{O}$ and develop the gel by immersing in a solution of freshly made $1.5 \% \mathrm{NaOH}, 0.01 \% \mathrm{NaBH}_{4}$, and $0.15 \%$ formaldehyde. (4) Fix the gel for 10 minutes in $0.75 \% \mathrm{Na}_{2} \mathrm{CO}_{3}$ and seal the gel in plastic. A protein is often carried over from the PCR reactions which can obscure bands of about $130 \mathrm{bp}$. This can be easily avoided by vortexing the PCR amplification with an equal volume of phenol/chloroform before gel loading. This technique offers significant advantages in safety, cost, and time compared with standard radioisotopic methods of detection.

\section{A strategy for the investigation of Duchenne and Becker muscular dystrophies in the diagnostic genetics laboratory based on accurate carrier detection}

\section{COCKBURN, I JOHNSON, J HOPKIN, A MICIAK}

Department of Medical Genetics, Churchill Hospital, Headington, Oxford $O X 37 L \mathcal{F}$.

We describe a strategy for the investigation of DMD which incorporates two techniques that provide accurate carrier diagnosis. The techniques are analysis using dinucleotide repeat markers and pulsed field gel electrophoresis (PFGE). The location of highly polymorphic CA repeat markers from a region of the DMD gene which is prone to deletion means that analysis using these markers yields information on the carrier status of women from approximately $30 \%$ of families. Where the above analysis is uninformative or not appropriate, PFGE analysis is performed. Altered sized restriction fragments which result from deletions/duplications can be detected and used as markers of the disease mutation in approximately a further $30 \%$ of families. By adopting the above strategy, we are able to provide accurate carrier diagnosis in approximately $60 \%$ of DMD families where an affected male is available for analysis. Many women are given negligible carrier risks and require no further laboratory investigations. Even in families where no affected male is available for analysis it is often possible to characterise mutations and to identify markers which will enable accurate prenatal diagnosis.

\section{Experience of DMD/BMD carrier detection by in situ hybridisation}

\section{N ROBINSON, R MOUNTFORD, L GAUNT}

Dept Medical Genetics, St Mary's Hospital, Manchester.

Our experience of carrier detection by in situ hybridisation initially involved the cosmid CPT 1 which contains exon 45 of the dystro- phin gene. Twenty-eight percent of our families had a suitable deletion involving all of this cosmid, and we were able to give definitive carrier risks (barring germinal mosaicism) to all women in these families. This included several women who had intermediate risks after DNA analysis. Where the deletion did not include all the cosmid, the interpretation of the results became subjective. This has implications for the use of FISH as a general method for carrier detection in families with a deletion. This method of carrier detection is very useful in conjunction with DNA analysis and we are actively working up other cosmids to make it applicable to more families.

\section{Different molecular mutations in male sibs with Duchenne muscular dystrophy}

\section{S PLAHA*, R A NEWBURY-ECOB $\dagger$}

Departments of Molecular Genetics* and Clinical Geneticst, Leicester Royal Infirmary.

We describe two brothers from an AfroCaribbean family affected by DMD. DNA analysis with genomic and $\mathrm{CDNA}$ probes did not detect a deletion but showed that the two boys had inherited different maternal $\mathrm{X}$ chromosomes. Analysis with probe pERT 87-8 showed a junctional fragment in one of the affected boys which was also present in the mother and grandmother. The other affected boy did not show the junctional fragment and had the same haplotype as his unaffected brother. This shows that the mutations causing the disease in the affected sibs are different, which explains their differing clinical symptoms. Our findings are similar to those reported recently by Miciak et al who described three related DMD males each carrying a different mutation on a different X chromosome. We also speculate that a transposon may be involved in disrupting the dystrophin gene in the family described here.

\section{Mutation detection in rhodopsin and peripherin genes in the Scottish retinitis pigmentosa population}

\section{BELL*, C CONVERSE $\dagger$, $M$ F COLLINS $\dagger$, L ESAKOWITZ $\ddagger$, K F KELLY*, NE HAITES*}

*Medical Genetics, Dept Molecular and Cell Biology, University Medical School, Foresterhill, Aberdeen AB9 2ZD. †Dept Pharmaceutical Sciences, University of Strathclyde, Glasgow G1 1XW. $\ddagger$ Eye Clinic, Royal Alexandra Hospital, Paisley.

Using single stranded conformation polymorphism (SSCP) analysis, we have analysed the candidate genes rhodopsin and peripherin in affected subjects of 17 autosomal dominant retinitis pigmentosa families and 17 isolated cases from the Scottish population. Mobility shifts in rhodopsin were detected in exons 1,3 , and 5 in 13,10, and seven subjects respectively. Shifts were detected in five subjects in exon 1 of peripherin. The nature of the shifts is at present being determined by direct sequencing, where initial results have shown that a mutation in exon 3 of rhodopsin segregates with the disease phenotype in an early onset dominant family. In seven simplex cases, the shifts are due to a polymorphism outside the coding region. Further sequencing studies will show the nature behind the remaining shifts. It is assumed, in line with current evidence, that additional rhodopsin and peripherin mutations will be detected in dominant families, and perhaps in isolated cases where they may represent new, dominantly inherited mutations.

\section{Predictive testing for \\ Huntington's disease: experience with the multiallelic probe pKP1.65}

\section{G H LINFORTH, D S PLAHA}

Molecular Genetics, Leicester Royal Infirmary, Leicester LE1 5WW.

Analysis of families with a history of HD currently involves the use of closely linked DNA markers of which the VNTR probes such as pKP1.65 (locus D4S43) have been the most informative. We have analysed 29 families and of the 20 families for which informative data have been obtained to date, 13 have been with pKP1.65. This high level of informativeness has been achieved by extended electrophoresis on $2 \%$ agarose. Optimisation of band separation has also shown the presence of further alleles in addition to the four commonly reported for this probe. We have currently detected at least eight alleles with this approach. We are confident that improved band resolution as achieved here could also be applicable to other VNTR probes and would greatly improve analysis of HD families.

\section{Predictive testing in a one generation Huntington's disease family}

\section{G H LINFORTH*, D S PLAHA*, J SHAKESPERE $\dagger$, J H ANDERSON $\dagger$, I D YOUNG +}

${ }^{*}$ Molecular Genetics, Leicester Royal Infirmary. †Department of Psychiatry, Leicester Royal Infirmary. $\ddagger$ Clinical Genetics Unit, City Hospital, Nottingham.

We were presented with a predictive test request for a member of a one generation $\mathrm{HD}$ family. Analysis of two affected sibs combined with anonymous testing of a number of further sibs with the VNTR probe pKP1.65 identified all four parental markers including the high risk allele. This provided the basis of a predictive test as requested while maintaining confidentiality of other family members' results. Resolution of the high risk allele was achieved by extended electrophoresis on $2 \%$ agarose. This was confirmed by combining DNA from both affected subjects resulting in three bands of which only one was common to both. We have successfully analysed a number of families that do not exhibit the ideal three generation pedigree structure, including several two generation families and one family in which DNA was not available from any affected subject. 
Wolf-Hirschhorn syndrome: paternal origin of a submicroscopic deletion of chromosome 4

\section{JOHN C S DEAN, M DAVIDSON, K KELLY, G S STEPHEN}

Department of Medical Genetics, Aberdeen Royal Hospitals NHS Trust, Foresterhill, Aberdeen.

Wolf-Hirschhorn syndrome (WHS) is a multiple congenital anomaly syndrome associated with deletion of chromosome 4 , band p16. An 11 year old female is described with severe pre- and postnatal growth deficiency, microcephaly, seizures, severe mental retardation, and prominent kyphosis. The characteristic facies was evident. High resolution karyotype showed no visible abnormality of chromosome 4. Southern DNA analysis using probe p157 showed that she had not inherited a paternal allele at locus D4S111. Probing with p252 (D4S115) and pBS731 (D4S98) was uninformative, but probes YNZ.32 (D4S125), pBS674ED (D4S95), and KP1.65 (D4S43) were not deleted. The proximal end of the deletion therefore lies between $D 4 S 111$ and $D 4 S 43$, about $2 \mathrm{Mb}$ from the telomere. This patient further exemplifies that in WHS, de novo deletions predominantly affect the chromosome 4 of paternal origin. In cases with familial translocations, published reports suggest that either parent may transmit the deleted chromosome. Investigation of a patient with suspected WHS should include DNA based analysis, as submicroscopic deletions are not infrequent.

\section{Molecular genetic studies of Angelman syndrome and Prader-Willi syndrome patients}

A COOKE*, J L TOLMIE*, CE CHU*十, J B P STEPHENSON‡, M D C DONALDSON $\dagger$, R DAY $\ddagger$, S GREENE $\$$, J M CONNOR*

\section{*Duncan Guthrie Institute of Medical Genetics, $\uparrow$ Department of Child Health, $\ddagger$ Assessment Unit, Yorkhill Hospital, Glasgow G3 8S7. §Department of Paediatrics, Ninewells Hospital, Dundee.}

DNA samples from AS or PWS patients and their parents were tested with the probes $D 15 S 9, D 15 S 10, D 15 S 11$, and $D 15 S 12$ by Southern analysis, and $G A B R B 3$ using PCR. Six out of nine AS patients were found to have one chromosome 15 homologue deleted for the probes tested, with the origin of deletion being shown to be maternal in all cases. One case was shown to result from paternal isodisomy, and no abnormality could be detected in the remaining two patients. Eleven out of 17 PWS patients were hemizygous for all probes tested, with the paternal origin of the deleted 15 being confirmed in nine cases. One patient was found to have one 15 deleted for $G A B R B 3, D 15 S 9$, and $D 15 S 10$, but to be heterozygous for D15S11 and D15S12. Saitoh et al recently reported a three generation family deleted for $D 15 S 10$ and $G A B R B 3$, affected by AS but not PWS. No abnormality was detected in four of the remaining PWS patients, and the results from the final patient indicate maternal heterodisomy, though this is yet to be confirmed.

\section{Mutation analysis in families with hyperkalaemic periodic paralysis}

\section{KATE J D STANNARD*, \\ STEPHEN ABBS*, \\ CHRISTOPHER G MATHEW* SHIRLEY HODGSON*, RICHARD HUGHES + , MARTIN BOBROW*}

\section{*Division of Medical and Molecular} Genetics, and $\uparrow$ Division of Neurology, United Medical and Dental Schools of Guy's and St Thomas's Hospitals, Guy's Hospital, London SE1 9RT

Members of a large family and a sporadic case of hyperkalaemic periodic paralysis (HYPP) have been examined for the presence of either of two described mutations in the gene coding for the $\alpha$ subunit of the adult skeletal muscle sodium channel (SCN4A). Assays involving PCR amplification and restriction digestion of products were used, and in the absence of samples known to carry the mutations, internal controls were incorporated into the assays to ensure the reliability of the results. In one case the presence of the mutation creates a restriction site, while in the other a modified primer was used which, in the presence of the mutation, introduces a restriction site into the products of PCR. The results obtained by PCR assay were confirmed by sequencing. The affected members in both families were each found to display one of the two mutations, suggesting that these are relatively common mutations in this disorder. Additionally, the mutation present in the large family was found to be associated with a phenotype of interattack muscle weakness, as described in all the previously reported cases with this mutation.

\section{Congenital myopathy with fibre type disproportion: a family with a chromosomal translocation $t(10 ; 17)$ may indicate candidate gene regions}

\section{A GERDES, M PETERSEN, H SCHRODER, K WULF, K BRONDUM-NIELSEN}

Dept of Clinical Chemistry, Pediatrics, and Pathology, Odense Hospital, Glostrup. Dept of Medical Genetics, Odense University, Denmark.

A child with severe congenital myopathy with fibre type disproportion was found to have an apparently balanced translocation $t(10 ; 17)(\mathrm{p} 11 ; \mathrm{q} 25)$. The same translocation was found in the clinically healthy mother, who nevertheless on EMG showed discrete signs of myopathy. Maternal uniparental heterodisomy was excluded by RFLP analysis of DNA markers on chromosomes 10 and 17. The regions are investigated further as candidate regions for a myopathy gene.
The screening of the fibrillin gene FBN1 for causal mutations in Marfan syndrome

D R HEWETT, J R LYNCH, R SMITH, A CHILD, B C SYKES

Collagen Genetics Group, University of Oxford, Institute of Molecular Medicine, fohn Radcliffe Hospital, Headington, Oxford OX3 9DU.

Marfan syndrome is a connective tissue disorder with an autosomal dominant pattern of inheritance manifesting in ocular, cardiovascular, and skeletal systems. It has been linked to the gene for the microfibrillar protein fibrillin and several missense mutations have previously been identified within this gene. Screening of the available gene sequence for further causal mutations has been carried out on a total of 16 patients by searching for single stranded conformational polymorphisms (SSCP). SSCP screening was carried out on PCR amplified fibrillin mRNA isolated from either fresh blood lymphocytes or cultured skin fibroblasts. Two patients were found to be heterozygous for point mutations that would result in missense mutations within two separate EGF-like repeats of the fibrillin protein: a cysteine to tyrosine substitution at codon 325 and an asparagine to a serine change at codon 1246 .

\section{Molecular analysis of the allelic expression of the cartilage} specific type II collagen gene COL2A1 in osteoarthritis

\section{J A LOUGHLIN, C M M IRVEN,} B C SYKES

Collagen Genetics Group, University of Oxford, Institute of Molecular Medicine, fohn Radcliffe Hospital, Headington, Oxford OX3 9DU.

Osteoarthritis (OA) is the most commonly diagnosed musculoskeletal disorder and is characterised by a progressive degeneration of articular cartilage. The major protein of cartilage is type II collagen which is encoded by the COL2A1 gene. Recently, COL2A has been linked to OA in two pedigrees. We have set out to determine whether a loss or reduction in the expression of COL2A1 in cartilage, with a subsequent reduction in the levels of type II collagen, could be a contributing factor in the aetiology of OA. Genomic DNA and RNA were extracted from the knee cartilage of OA patients undergoing knee replacement. By direct sequence analysis of polymerase chain reaction (PCR) amplified genomic DNA, we assessed which patients were heterozygous for two sequence dimorphisms, one located in exon 50 and the other in the $3^{\prime}$ UTR of COL2A1. The COL2A1 cDNA regions encompassing the sequence dimorphisms were then amplified by reverse transcription-PCR (RT-PCR) of cartilage RNA. The expression of each dimorphic allele in heterozygotes was then determined by restriction digestion and primer extension analysis. Using this technique, we have observed differential expression of COL2A1 alleles in the cartilage of some OA patients. 